\title{
Pros and Cons of Self Driving Vans - A Real Life Motorway Case Study Analysis from Great Britain
}

\begin{abstract}
A B S T R A C T
Given the speculations that autonomous vehicles are sure to take over the transport sectors in the near future, this study micro-simulates the impacts of automating the freight vehicle VAN using the micro-simulation software AIMSUN at SAE Level 4 on an existing motorway network in the United Kingdom using real road network conditions and traffic information. This study analyses the impacts of automation of vans in different levels of automation penetrations $(0 \%, 25 \%, 50 \%, 75 \%, 100 \%)$ with heterogeneous traffic conditions on traffic parameters such as speed, time and different environmental factors such as CO2, NOx, PM and VOC. For better understanding the impacts of automation, analysis along the motorway was carried out along different stretches of the motorway between two junctions. In this study, the impacts of automation of van in different road characteristics such as congested stretches, stretches with slope and flat stretches were also analyzed in detail. The study highlights that with an increase in van automation penetrations, traffic parameters such as speed and time are positively impacted while negative impacts on environmental conditions are observed along the motorway stretches.
\end{abstract}

K E Y W O R D S

Traffic Simulation, Micro Simulation, Autonomous Vehicles, Vehicle Connectivity, Environmental Emission

Introduction

$1.1 \quad$ Background

Traffic congestion has always been an area of rigorous concern for both urban planners and traffic engineers as the development of various infrastructural facilities gets adversely impacted by them. With the wide technological innovations and advancements occurring in the present-day field of automated vehicles, these concerns are sure to skyrocket soon [1]. The General Motors and Radio Corporation of America Sarnoff Laboratory first carried out and initiated the idea of autonomous vehicles in the 1950s [2]. Wadud et al. and Flamig [3,4] reported that shortly, private methods of transportation and shared taxi services of transportation will see a major boost in the domain of Automated Driving Systems (ADS) which is going to transform the way people move on the road. The considered main advantage of autonomous vehicles is that they can be used both as a private and as a commercial (taxi) vehicle [5 - 16]. Users with mobility limitations such as the children, sick, elderly, etc. $[17,18,19]$ are forecasted to be highly benefited by vehicle automation. In general, AVs are expected to be cheap, reliable, comfortable and bring about more normalized flows, steady speed outline, reduction in accidents caused by human negligence, more uniform travel behavior, reduced travel time, time use benefits, etc. [19-22]. But these benefits that are going to be introduced by the automation of freight vehicles are forecasted to bring about higher levels of traffic congestion especially with the current road infrastructure and their behavior with the existing conventional vehicles [24-26].

This study looks into the impact of highly automated SAE level 4 (Appendix A) freight VANs on travel time/delay, speed, and environmental impacts on an already existing motorway in the UK. The study also analyses how speed and time are impacted by the inter-vehicular gaps and convoy length when CACC abilities are provided for a group of automated SAE Level 4 Vans. The different levels of automation penetration (25\%, 50\%, 75\%, and 100\%) for vans with heterogeneous traffic conditions having conventional cars, vans, and trucks (belonging to 3 different types) are addressed in this study. Thus, the impact of higher levels of van automation when in co-existence with the conventional vehicles are analyzed with the introduction of automation penetration in different penetrations.

This study aims to reduce the gap that currently exists in the body of literature that discusses the impacts of highly automated (SAE Level 4) vans on real road network conditions. This study analyses the impacts of higher levels of automated vans on speed, travel times and environmental factors in motorway driving by enabling platooning of similar vans through the vehicle to vehicle communication (CACC). Thus, in this study, the M62 motorway which has a substantially-high percentage of vehicle movements is selected to analyze the impacts of automated vans with heterogeneous mixed traffic conditions. The selected stretch of M62 features a comparably flat section with a considerable climb vehicle flows which is kept to the current road network conditions using the information obtained from Highways England. Vans were provided with automated capabilities and penetrated at 25\%, 50\%, $75 \%$, and $100 \%$ automation in the microsimulation software AIMSUN. The automated capability was the ability of 
Vans to begin a process of ad hoc coupling with other similarly automated vans with a closing distance of 200 meters. Coupling was carried out through Cooperative Adaptive Cruise Control (CACC) and was maintained through intersections, except when a coupled vehicle had to exit the motorway.

\subsection{Research Objectives}

The main objective of this study is to analyze the various impacts that high levels of automated (SAE level 4) vans have on an already existing motorway. The various objectives include understanding the

- the impact of high-level van automation on overall traffic parameters such as speed and time

- impacts of high-level van automation on environmental emission factors (Using London Emission Model) with respect to Carbon-Dioxide (CO2), Nitrogen Oxide (NOx), Particulate Matter (PM), and Volatile Organic Compound (VOC).

- effects of gap distance and convoy length of automated cars (CACC) on motorway speed

- effects of gap distance and convoy length of automated cars (CACC) on emission

\section{Methods and Materials}

\subsection{Scope of the Study}

Even though there exists a surplus body of literature corresponding to the impacts of automated cars and other private vehicles (typically of SAE Levels -1 and 2), the body of literature incorporating the impacts of highly automated (SAE level 4 and above - Appendix A) freight vehicles especially vans with mixed traffic conditions on a real road network conditions are limited. Thus, in this study, the M62 motorway which has a substantially-high percentage of freight movements is selected to analyze the impacts of automated vans with heterogeneous mixed traffic conditions on delay/travel time, traffic speed and environmental emission aspects. This study focuses on reducing the above-mentioned gap in the literature by analyzing the impact of higher levels of automated vans with heterogeneous traffic conditions on an existing motorway traffic flow using real road network conditions \& information obtained from Highways England by the method of micro-simulation modeling.

\subsection{Study Area}

Motorways are the network of trunk roads administrated by Highways England in the United Kingdom (ICE (2020)). For the purpose of this study, the stretch of M62 motorway situated to just further Junction 22 towards westbound of Leeds (Junction 28) \& towards Manchester at the top of the Pennine mountain range was selected. M62 is one of the main stretches of trunk roads in the UK linking wider European networks via Rotterdam and Dublin also covering other prominent urban areas in England such as the Hull, Leeds, Bradford, Manchester, and Liverpool.

Motorways with sections of entry and exit ramps of M606 and M621 motorways were merged with M62. The flat section which is $73 \mathrm{~m}$ above sea level from Leeds to Brighouse (Junction 25) increases to $230 \mathrm{~m}$ above sea level at Pennines (Junction 22). Hence the impact of automation on normal, congested, and up-hill stretches can be analyzed from this selected motorway without having the need to run multiple motorway simulations. The leftmost lane is considered to be the slow lane in the UK and that the highest elevation observed in the motorway of England $(372 \mathrm{~m})$ is observed at the selected stretch at the east of Junction 22. 


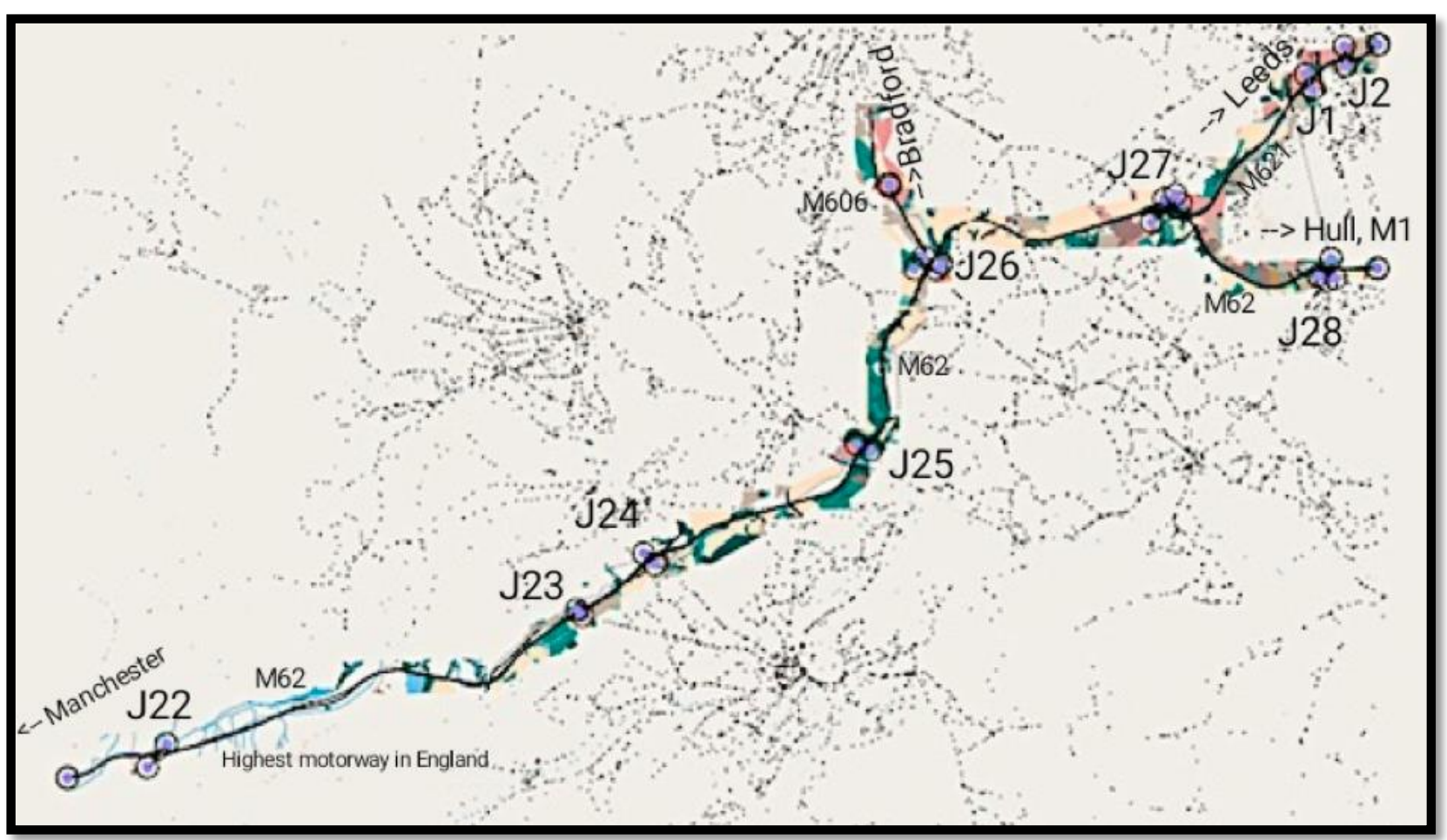

Figure 1: M62 Motorway (Study Area)

Note: *Source - From Micro-simulation conducted in AIMSUN by the author

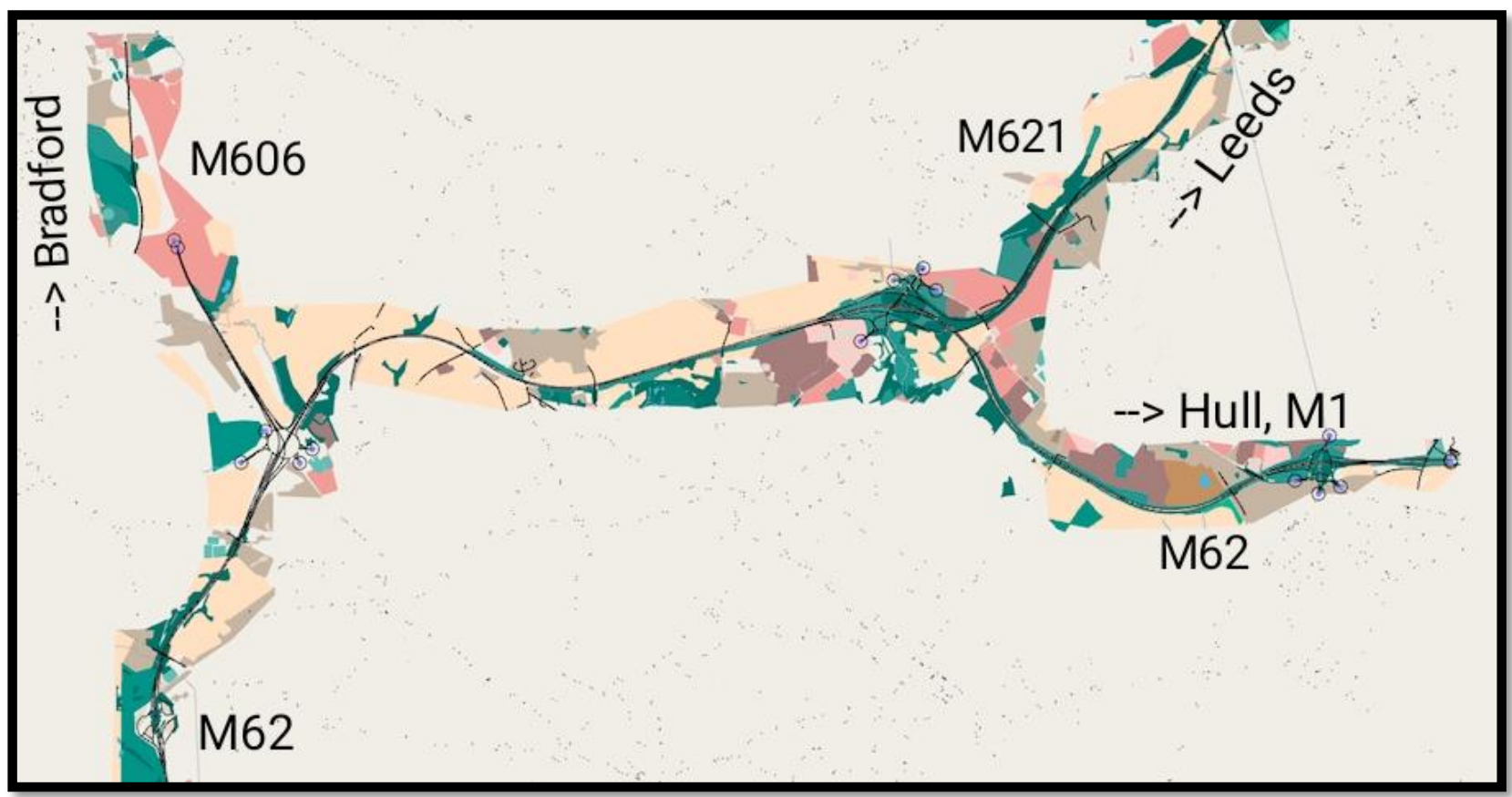

Figure 2: The merging of motorways M606 and M621 into M62

Note: *Source - From Micro-simulation conducted in AIMSUN by the author

Figure 1 shows the chosen stretch of motorway M62 for simulation using the micro-simulation software Aimsun. The merging of motorways M606 and M621 into M62 is shown in Figure 2. The varying levels of congestion that 
can be observed in the selected stretch of motorway allow analyzing the impact of different levels of automation of different vehicles in traffic flow. The uphill stretch located near Junction 22 allows observing the impacts of speed, delay, and environmental emission behavior of automated vans in the uphill portions

\subsection{Simulation Setup}

A conscious decision to not include any potential demand implications of van automation in the total traffic demand was made. Therefore, any possible changes to the total vehicle volume that might occur as a result of vehicle automation due to the changes in the relative prices of vehicle transportation are not considered. For this study, the traffic demand replicates the current real road network conditions of the considered motorway according to the data obtained from Highways England.

\subsubsection{Simulating Vehicle Behavior}

For the purpose of simulation, traffic flow data was collected from Highways England. Traffic counts were provided on the basis of loop data. Micro-simulation software Aimsun version 8.3 was used for simulation of automated and non-automated vehicles in the motorway stretch M62 (Figure 1). Given that there is only less available literature that co-operates higher levels of automated vans with other types of conventional vehicles, vehicle types belonging to the classification of vans were assumed to be automated in existing mixed traffic conditions in our simulation.

The entire stretch of M62 given in figure 1 from just above junction 22 to just above junction 2 and 28 was simulated in the micro-simulation software Aimsun. Details of junctions, their exits, and entries, sometimes including details of associated roundabouts along with traffic flow data was incorporated in Aimsun while simulating the motorway characteristics. Some minor adjustments were made for maintaining the consistency of the traffic across the junctions since the on-ramp and off-ramp data for every junction was not always available so that it did not impact the overall simulation flows. The merging of the M606 and M621 with M62 is shown in figure 2. The simulation was carried out between 0700-0800 hours for one hour during the morning peak traffic in the selected motorway stretch M62.

The classes of vehicles used in the simulation were classified according to the vehicle length as per the motorway count measurement system which is given in Table 1. Even though we have three types of trucks (light, rigid and articulated) as given in Table 1, the impacts of automation of vans are assumed to penetrate at a similar rate for all the three groups together mentioned as Trucks in our study. Traffic flow is measured for this classification of vehicle classes and each class was given automation capability in different levels of penetration in the simulation.

Table 1: Vehicle Classification

\begin{tabular}{|l|l|}
\hline Vehicle Classes & Vehicle Length \\
\hline Cars & $<=5.2 \mathrm{~m}$ \\
\hline Vans & $>5.2 \mathrm{~m}$ and $<=6.6 \mathrm{~m}$ \\
\hline Light Commercial Vehicles (light trucks) & $>6.6 \mathrm{~m}$ and $<=11.6 \mathrm{~m}$ \\
\hline Large trucks: they are split into 50\% rigid and 50\% articulated & $>11.6 \mathrm{~m}$ \\
\hline
\end{tabular}

Gips model of car-following is used by the micro-simulation software Aimsun [27]. Aimsun's default parameters were applied for simulating the standard (non-automated) vehicles. Some minor adjustments were made in order to reflect UK specification regulations and to calibrate against the mean speed of different classes of vehicles at individual sections of the motorway. The mean speed limit of automated vans was increased when compared to conventional vans since automated vehicles are predicted to have higher speed profiles. Table 2 shows the speed profiles for automated and standard vehicle classes. 
Table 2: Vehicle Speed Profile

\begin{tabular}{|l|l|l|l|l|}
\hline Vehicle Type & Mean Speed & $\begin{array}{l}\text { Standard Deviation } \\
\text { (Speed) }\end{array}$ & Minimum Speed & Maximum Speed \\
\hline Car & $110 \mathrm{~km} / \mathrm{h}$ & $10 \mathrm{~km} / \mathrm{h}$ & $80 \mathrm{~km} / \mathrm{h}$ & $150 \mathrm{~km} / \mathrm{h}$ \\
\hline Van & $100 \mathrm{~km} / \mathrm{h}$ & $10 \mathrm{~km} / \mathrm{h}$ & $80 \mathrm{~km} / \mathrm{h}$ & $120 \mathrm{~km} / \mathrm{h}$ \\
\hline Truck & $85 \mathrm{~km} / \mathrm{h}$ & $10 \mathrm{~km} / \mathrm{h}$ & $70 \mathrm{~km} / \mathrm{h}$ & $90 \mathrm{~km} / \mathrm{h}$ \\
\hline Automated Van & $110 \mathrm{~km} / \mathrm{h}$ & $0 \mathrm{~km} / \mathrm{h}$ & $110 \mathrm{~km} / \mathrm{h}$ & $110 \mathrm{~km} / \mathrm{h}$ \\
\hline
\end{tabular}

The comparison of actual traffic flow and simulated flow for standard vehicles are given in Table 3. Table 4 and Table 5 show the desired deceleration and acceleration profiles for each vehicle classifications respectively. Table 6 shows the assumed weights of considered vehicles in the simulation.

Table 3: Average Simulated vs. Measured Flows Along the Stretch (veh/hr)

\begin{tabular}{|l|l|l|l|l|}
\hline Vehicle & Measured Flow & Simulated Flow & Measured Flow & Simulated Flow \\
\hline Car & & & & \\
\hline Van & J28- J27 & J28- J27 & J27 - J26 & J27 - J26 \\
\hline Truck & 2407.666 & 2415.3 & 2742.7333 & 2748 \\
\hline & 1203.333 & 1204.4 & 1371.3666 & 1379.9 \\
\hline Car & 852 & 858.1 & 1045.4 & 1045.2 \\
\hline Van & J26- J25 & J26- J25 & J25- J24 & J 25 - J24 \\
\hline Truck & 2037.7143 & 2076.3 & 1841.7777 & 1868.9 \\
\hline & 1011.8571 & 1014 & 920.888 & 916.1 \\
\hline Car & 809.42857 & 808.6 & 654.666 & 658.5 \\
\hline Van & J24- J23 & J24- J23 & J23- J22 & J23 - J22 \\
\hline Truck & 1413.555 & 1438.5 & 1736.5 & 1762.6 \\
\hline
\end{tabular}


Table 4: Deceleration Profiles of Vehicles

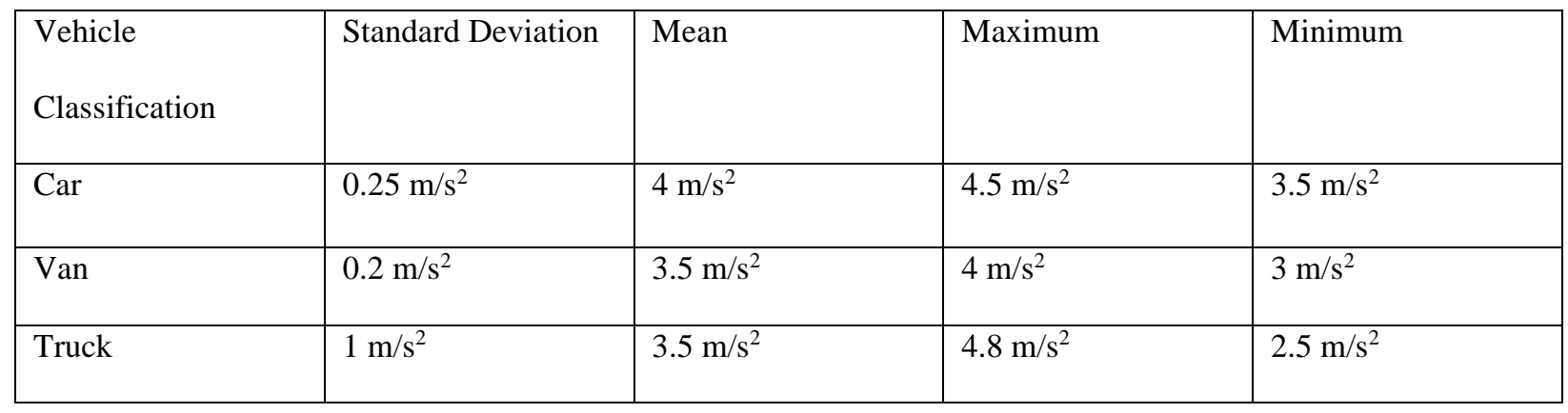

Table 5: Acceleration Profiles of Vehicles

\begin{tabular}{|l|l|l|l|l|}
\hline Vehicle & Standard Deviation & Mean & Maximum & Minimum \\
\hline Car & $0.2 \mathrm{~m} / \mathrm{s}^{2}$ & $3 \mathrm{~m} / \mathrm{s}^{2}$ & $3.4 \mathrm{~m} / \mathrm{s}^{2}$ & $2.6 \mathrm{~m} / \mathrm{s}^{2}$ \\
\hline Van & $0.2 \mathrm{~m} / \mathrm{s}^{2}$ & $2.5 \mathrm{~m} / \mathrm{s}^{2}$ & $3.0 \mathrm{~m} / \mathrm{s}^{2}$ & $2.0 \mathrm{~m} / \mathrm{s}^{2}$ \\
\hline Truck & $0.5 \mathrm{~m} / \mathrm{s}^{2}$ & $1 \mathrm{~m} / \mathrm{s}^{2}$ & $1.8 \mathrm{~m} / \mathrm{s}^{2}$ & $0.6 \mathrm{~m} / \mathrm{s}^{2}$ \\
\hline
\end{tabular}

Table 6: Vehicle Weight Profile

\begin{tabular}{|l|l|l|l|l|}
\hline Vehicle & Standard Deviation & Mean & Maximum & Minimum \\
\hline Car & & & & \\
\hline Van & $454 \mathrm{~kg}$ & $1202 \mathrm{~kg}$ & $2291 \mathrm{~kg}$ & $839 \mathrm{~kg}$ \\
\hline Light Truck & $9072 \mathrm{~kg}$ & $13608 \mathrm{~kg}$ & $40823 \mathrm{~kg}$ & $4536 \mathrm{~kg}$ \\
\hline Heavy Truck & $22680 \mathrm{~kg}$ & $13608 \mathrm{~kg}$ & $36287 \mathrm{~kg}$ & $4536 \mathrm{~kg}$ \\
\hline Articulated Truck & $22680 \mathrm{~kg}$ & $13608 \mathrm{~kg}$ & $46287 \mathrm{~kg}$ & $4536 \mathrm{~kg}$ \\
\hline
\end{tabular}

In order to depict the real-life scenarios as seen on a real motorway, certain parameters that are related to desired speeds of the vehicles across the network were slightly modified. Depending on the speed limit of the road in which the class of vehicle traverse, the desired speeds would change so that the vehicles could travel faster as seen in a real motorway (Table 7). For automated vans that are considered in the micro-simulation, they would always follow the speed limit as given in Table 7. The reaction time of each classification of the vehicle is given in Table 8 
Table 7: Speed Acceptance of Vehicle

\begin{tabular}{|l|l|l|l|l|}
\hline Vehicle & Standard Deviation & Mean & Maximum & Minimum \\
\hline Car & 0.1 & 1.1 & 1.3 & 0.9 \\
\hline Van & 0.1 & 1 & 1.15 & 0.9 \\
\hline Truck & 0.1 & 1.05 & 1.1 & 1 \\
\hline Automated Van & 0 & 1 & 1 & 1 \\
\hline
\end{tabular}

Table 8: Reaction Time of Vehicle

\begin{tabular}{|l|l|l|}
\hline Vehicle Classification & Reaction Time & Probability \\
\hline Car & $0.8 \mathrm{~s}$ & 0.8 \\
\hline Car & 0.2 & 1.2 \\
\hline Van & $0.8 \mathrm{~s}$ & 1 \\
\hline Truck & $0.8 \mathrm{~s}$ & 1 \\
\hline Automated Van & $0.4 \mathrm{~s}$ & 1 \\
\hline
\end{tabular}

The behavior of automated van for the purpose of micro-simulation of traffic flow along the motorway is modeled as follows:

- For an automated van, the reaction time is lesser than the human reaction time (Table 8)

- Speed distribution of automated van is more uniform as given in Table 7 since non - uniformity in human behavior can be overcome through the automation of vehicles

- $\quad$ Speed limits given in Table 7 is $100 \%$ followed

- London Emission Model in the micro-simulation software Aimsun is used to analyze the environmental impacts of automation

\subsection{Modelled Scenarios}

2.4.1 Van Automation at Different Penetrations at a Time

Analysis of automation penetration was made for the group of scenarios where only the vehicle classification van was automated for different penetration levels at a single time.

Table 9: Modelled Scenarios - Van Vehicle Classification Automated

\begin{tabular}{|l|l|l|l|l|l|l|}
\hline SI & Vehicle Classification & \multicolumn{5}{|l|}{ Percentage of Automation Penetration } \\
\cline { 3 - 7 } No & & $0 \%$ & $25 \%$ & $50 \%$ & $75 \%$ & $100 \%$ \\
\hline
\end{tabular}




\begin{tabular}{|c|c|c|c|c|c|c|}
\hline 2.4 .1 & Only Van & $\sqrt{ }$ & $\sqrt{ }$ & $\sqrt{ }$ & $\sqrt{ }$ & $\sqrt{ }$ \\
\hline 2.3 .2 & $\begin{array}{l}\text { Maximum platoon size of } 4 \text { vehicles } \\
\text { and inter-vehicle gap of } 4 \text { meters }\end{array}$ & & & & & $\sqrt{ }$ \\
\hline 2.3 .3 & $\begin{array}{l}\text { Maximum platoon size of } 3 \text { vehicles } \\
\text { and inter vehicle gap of } 10 \text { meters }\end{array}$ & & & & & $\sqrt{ }$ \\
\hline
\end{tabular}

Here the vehicle classification "Van" is automated at different penetrations $(0 \%, 25 \%, 50 \%, 75 \%, 100 \%)$ while the other vehicle types "Car" and "Truck" are kept non-automated throughout the study. In the above-mentioned table 9, $0 \%$ of automation penetration indicates the current real-life traffic demand on the motorway M62 network with $100 \%$ conventional vehicles. The results from $0 \%$ automation penetrations were used as a baseline to compare and understand the impacts that further levels of automation penetration have on traffic parameters and various environmental emission factors in our study. Similarly, 25\% automation of vans indicates that out of the considered $100 \%$ conventional vans, $25 \%$ of the total vehicle type vans are converted to autonomous vehicles and given SAE level 4 automation capabilities in simulation while the rest $75 \%$ of the vehicle type remains non-automated. Thus, in this particular scenario, various analysis such as effects on overall traffic parameters (speed and time), impacts of gap length, convoy length and environmental emission analysis is carried out while the vehicle type cars are automated at different penetrations, while the impact of automation of cars on non-automated vehicles are also analyzed in detail. Scenarios 2.3.2 and 2.3.3 are simulated in-order to understand the impacts of gap distance and convoy length of vehicle to vehicle communication through CACC on complete automation of cars.

\subsection{Data Processing}

The various simulations that were conducted in the simulation software were saved with the help of API files from Aimsun. 10 replications from each scenario were simulated to make sure that the data obtained from the simulations were reliable. Different factors such as the simulated vehicle ID, vehicle type, Junction ID, Lane ID, position, speed, total distance covered, etc. were collected from each simulation. The collected data were then processed and the average data from the 10 replications of each scenario were taken for this study.

\section{RESULTS AND DISCUSSION}

\subsection{Introduction}

The simulation results for the different scenarios are presented for smaller stretches of the motorway between two junctions in order to understand and identify the different vehicle behaviors and environmental impacts along different stretches. Stretch 27 - 26 (J27 - J26) is the heavily congested stretch, 26 - 25 (J26 - J25) is the moderately congested stretch, stretch $24-23$ (J24 - J23) is the uphill stretch, and stretch $23-22$ (J23 -J22) is the mild uphill stretch. Inferences on the impact of automation in different road geometry (uphill or not), traffic conditions (congested or not), and environmental factors were made without having the need to run different simulations for understanding the impact of automation in different road network characteristics.

\subsection{General Analysis}

The mean speed represented below in the figures is the average speeds of the vehicles that are taken into consideration for the simulation. Environmental emission factors such as Carbon-Dioxide (CO2), Nitrogen Oxide (NOx), Particulate Matter (PM), and Volatile Organic Compounds (VOC) was analyzed along the stretch of motorway. To determine and examine the different emission factors along the considered stretches, London Emission Model in the micro-simulation software Aimsun was used. With the increase in penetration of automated vehicles, hints of certain trends for the emission factors for different stretches of the motorway with almost similar property could be observed. For each scenario, it can be observed that the greatest emissions along M62 happen at the most congested stretch i.e. J27 - J26 as expected. Stretch 27 - 26 (J27 - J26) is the highly congested stretch due to the merging of M621 into M62 and stretch $26-25$ (J26 - J25) is the moderately congested stretch due to the 
merging of M606 into M62, stretch 24 - 23 (J24 - J23) is the uphill stretch and stretch 23 - 22 (J23-J22) is the mild uphill stretch.

\subsubsection{Analysis of Higher Level of Van Automation}

\section{Mean Speed.}

Figure 3 represents the impact of different levels of automation penetration of vehicle type van on traffic speed on the motorway M62. The other vehicle types cars and trucks are kept non-automated throughout the stretch on M62. From the different subfigures shown in fig 3, improvements in mean speed for the vehicle type van can be observed as the automation penetration increase i.e. as more and more vans are automated, the mean speeds of vehicle type van also increase. Noticeably, as more and more vans are automated, it can be observed that the mean speed of nonautomated vehicles also positively being impacted by the increase in automation penetration, although this increase is negligible. Overall, van vehicle automation improves the travel speed of vehicle type van and does not have any adverse impacts on the speeds of other vehicles.

With respect to the increase in automation penetration, there is some observational hint of non-linearity in the improvements in the mean speed of vans. In normal conditions, it can be observed that the improvements at higher automation penetration are greater than the speed increases at lower automation penetration. In congested situations, as in J27 - J26 and J26 - J25 (Figures 3a and 3b), this non- linearity becomes more prominent at an earlier level of penetration.

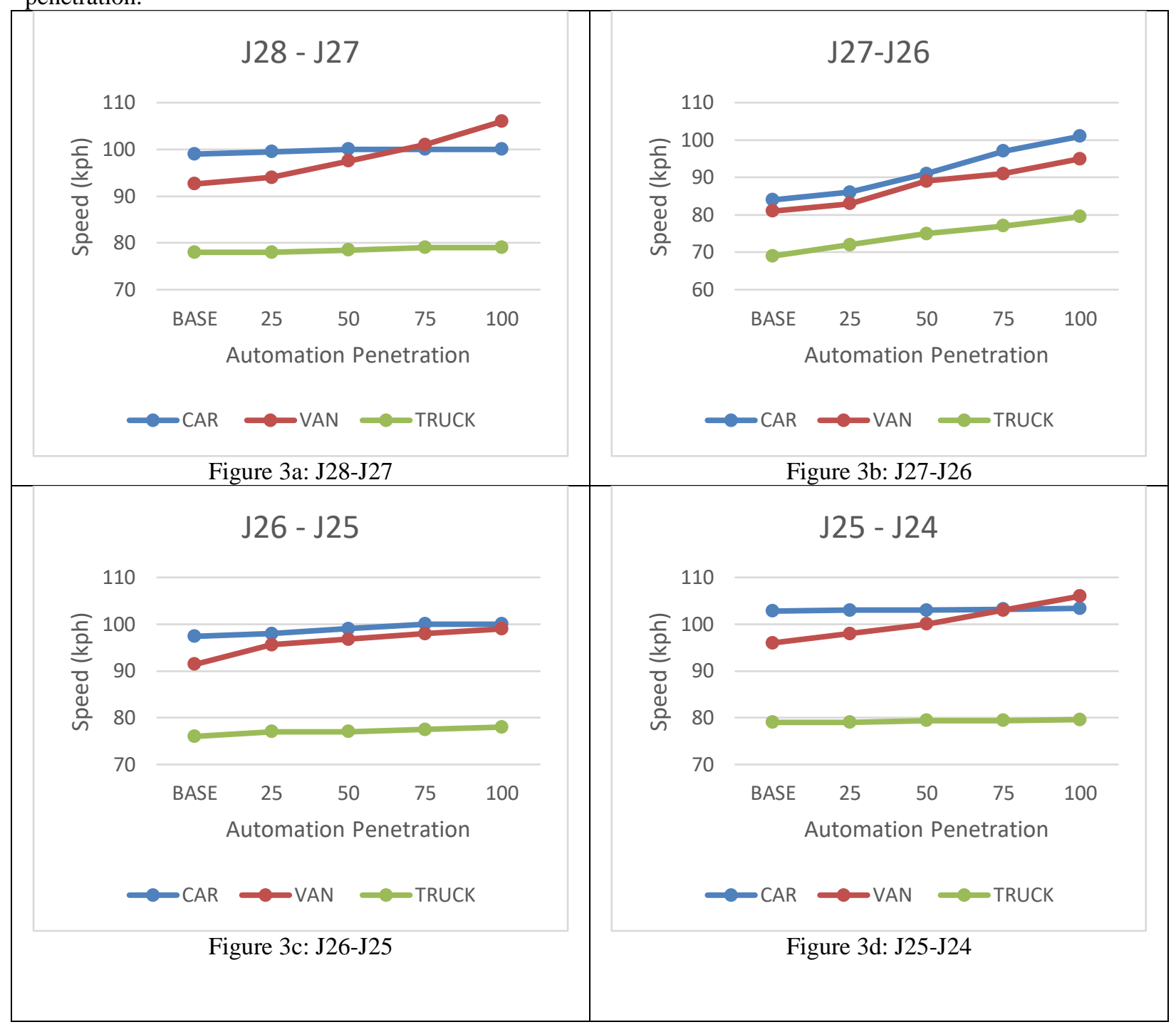




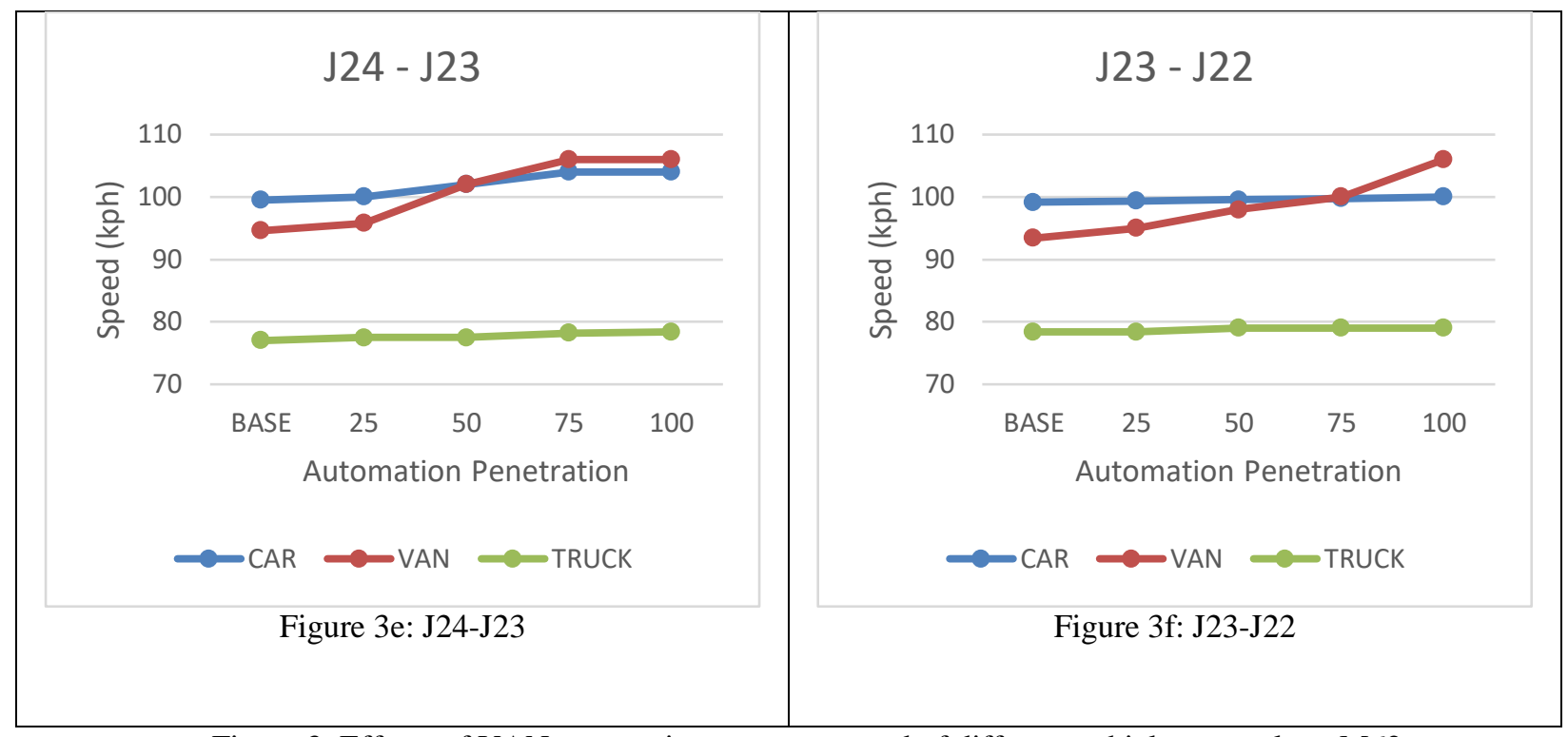

Figure 3: Effects of VAN automation on mean speed of different vehicle types along M62

From fig 3, it can be noted that the largest benefits in terms of greater mean speeds are observed in congested situations (fig 3b). The congested stretch J27 - J26 falls just after the merging of the two motorways M621 and M606 with the M62. An increase of 14.7\% in mean speed of vehicle type van is observed when all of them become automated compared to none of them being automated i.e. $0 \%$ automation. Noticeably, this substantial increase in mean speed of vans also improves the mean speed of cars and trucks in congested stretches by $16.8 \%$ and $13.2 \%$ respectively. It can be noted that just for congested stretches, the vehicle type cars are more benefitted with respect to mean speed when vans are automated. This might be possibly due to the less amount of conflicts between the vehicles due to automation and the higher amount of the vehicle type car along the stretch. Since the stretch J27 J26 lies between 2 other motorways merging at both ends (M621 and M601), this stretch also has substantial weaving traffic. In comparison, only less than $4 \%$ improvement for cars and trucks with respect to mean speed can be observed along the normal stretches of the considered motorway whereas a minimum of $7 \%$ increase in mean speeds for the vehicle type vans is observed along the stretch of the motorway. From fig $3 \mathrm{e}$ and $3 \mathrm{f}$ it can be observed that even along uphill stretches the mean speed of the vehicle type van gets benefited without any negative impact on the mean speed of other non-automated vehicle types.

\section{Normalized Time.}

Figure 4 represents the impact that different levels of automation penetration of vans have on the total time taken for traveling different stretches of the motorway. In-order to take into consideration that the different considered stretches have different lengths and that will impact the total travel time along the considered stretches, the travel times are normalized with respect to mean travel time by all vans with no automation (baseline). Similar results as observed in fig 3 can be observed in fig 4 as well. Automation of vans reduces the travel time of cars, as well as trucks along the stretch of the motorway and the reduction in travel time is more evident for congested stretches of the motorway compared to the rest of the motorway. 


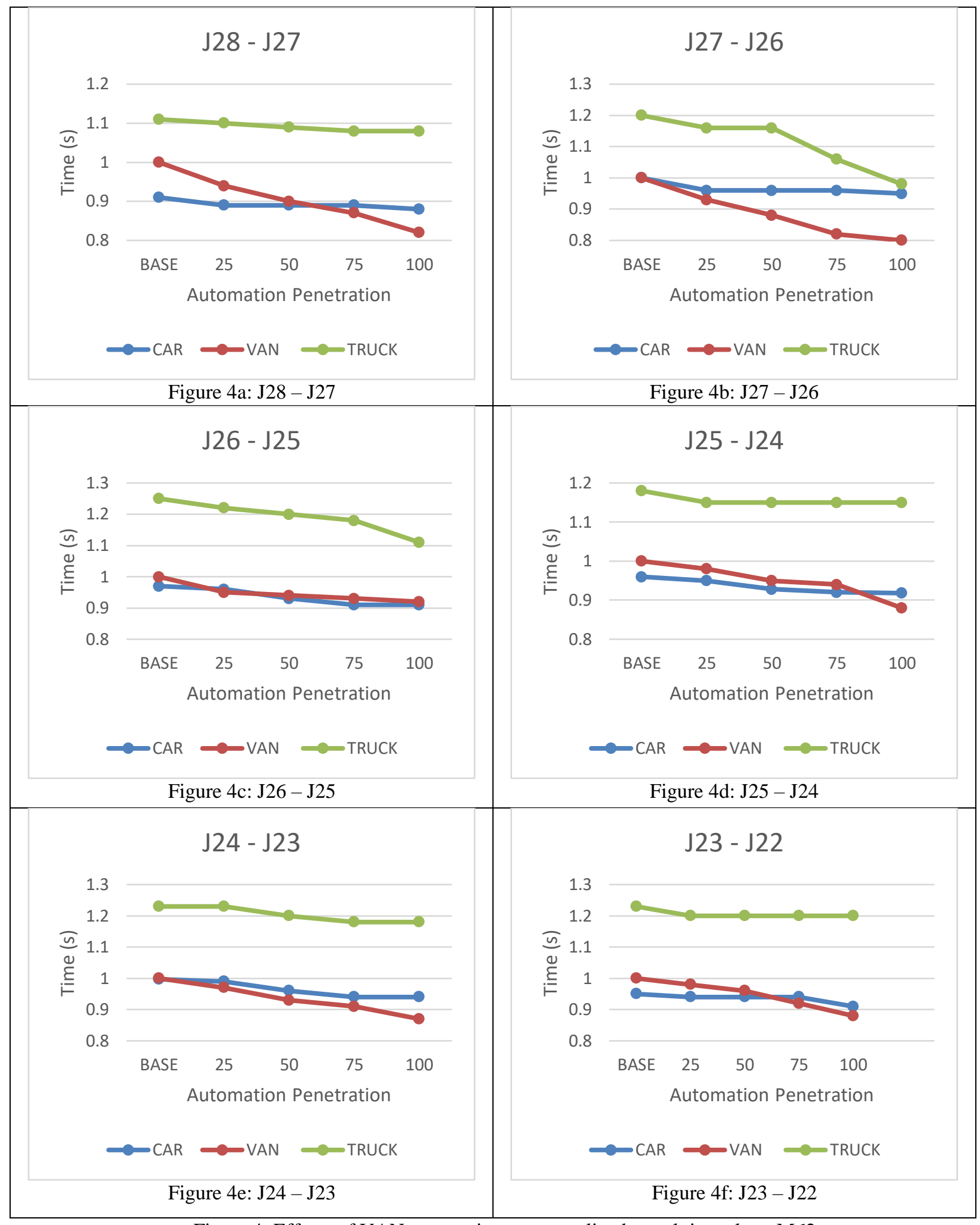

Figure 4: Effects of VAN automation on normalized travel time along M62 
Environmental Emission.

Figure 5, 6, 7, 8 represents the total emission concentration of the stretches when vans are automated on the simulated stretch M62. From stretches, where possible, inferences on the impact of automation with respect to environmental emission in different road geometry (uphill or not) and traffic conditions (congested or not) were made.

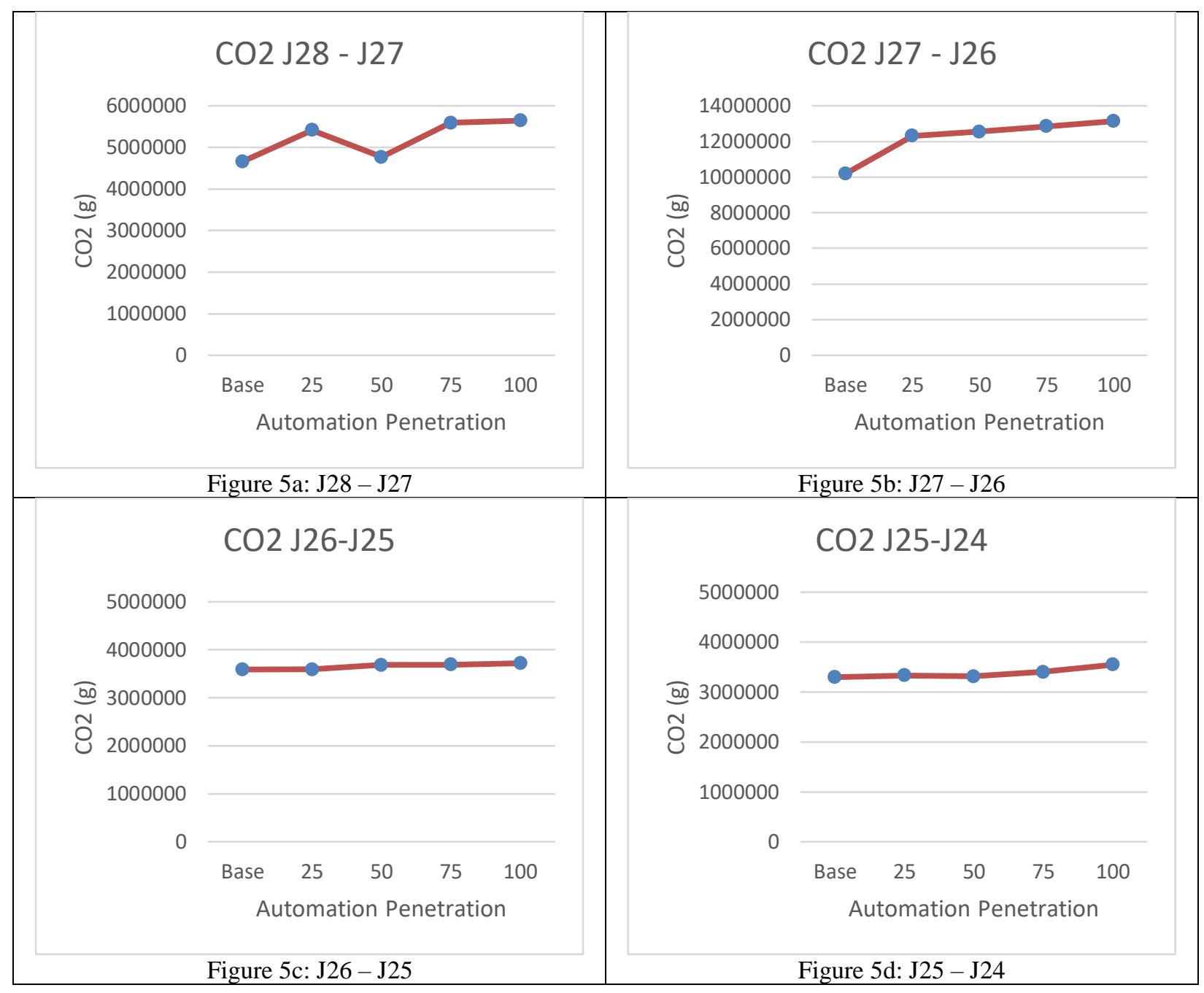




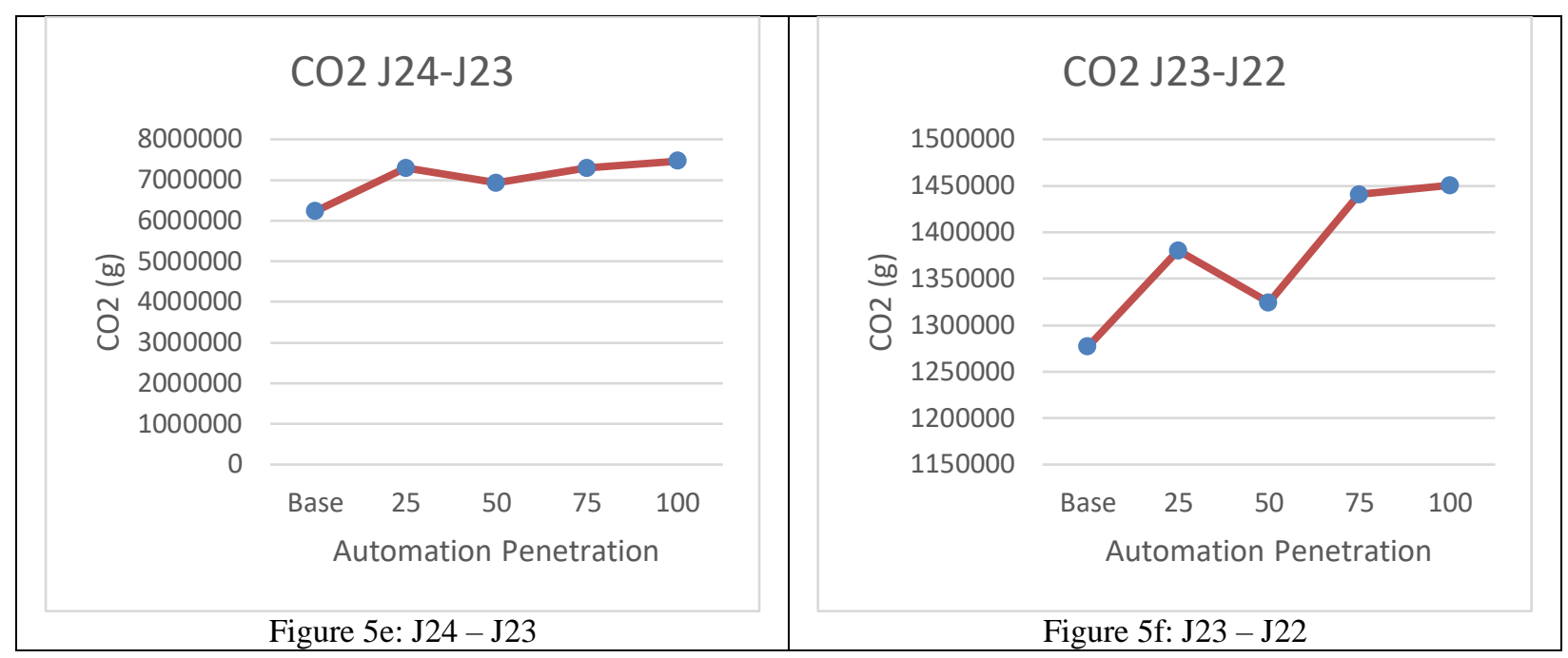

Figure 5: Effects of VAN automation on total carbon-dioxide emission along M62

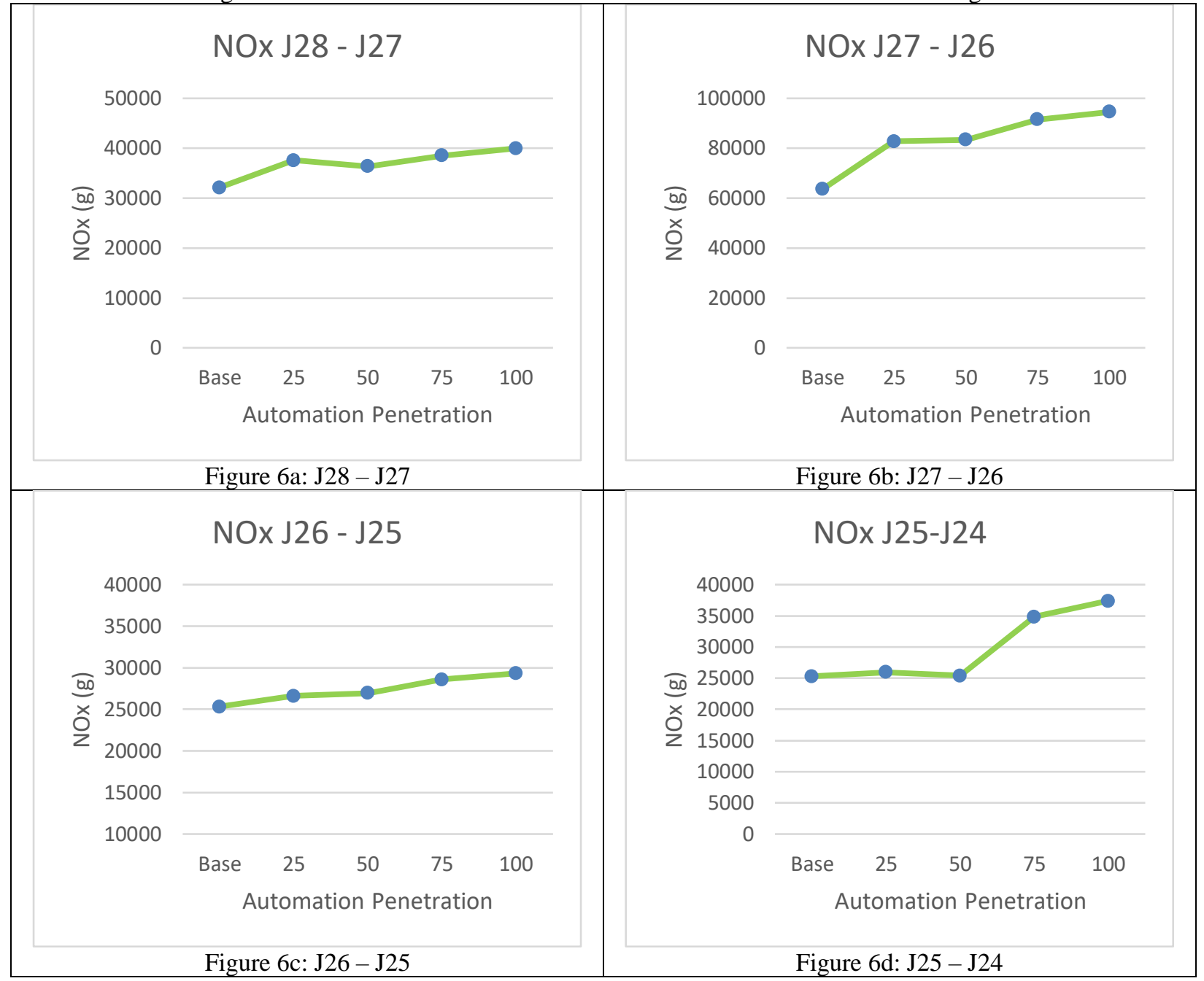




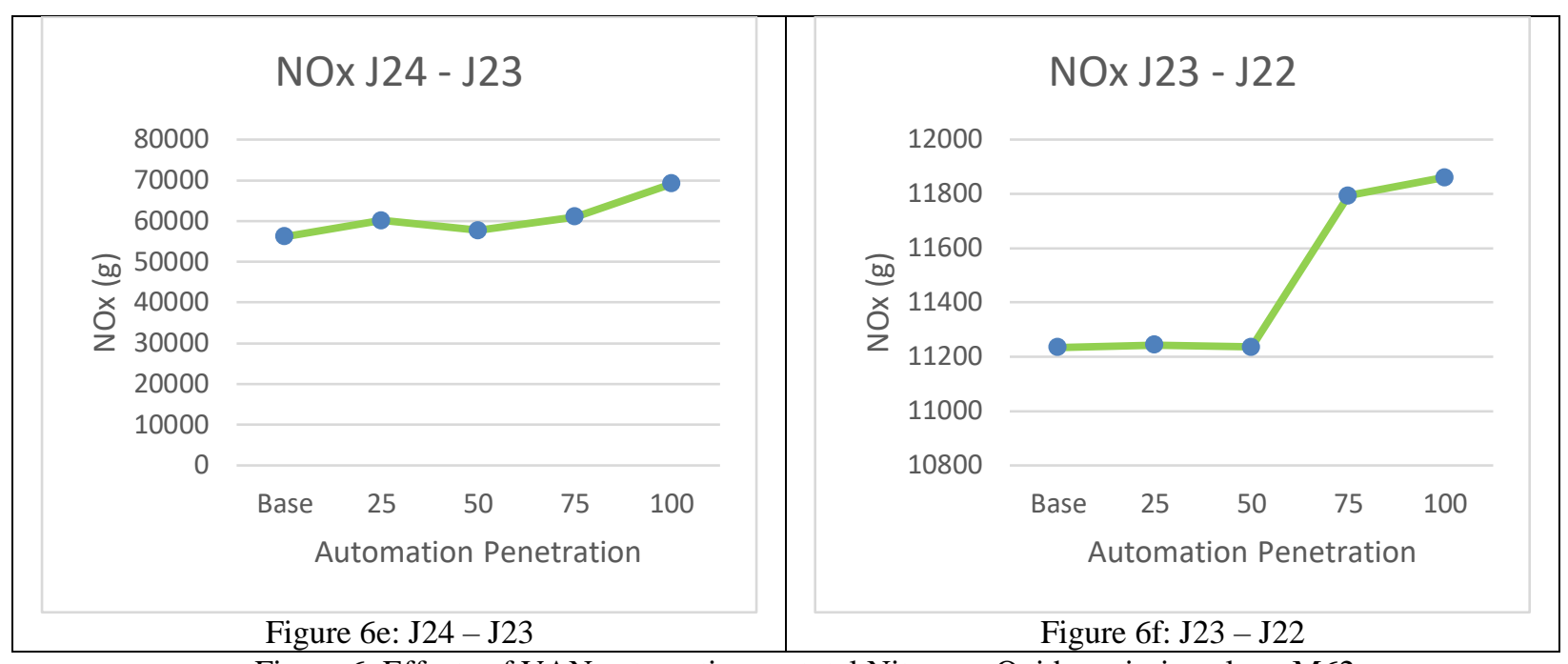

Figure 6: Effects of VAN automation on total Nitrogen-Oxide emission along M62

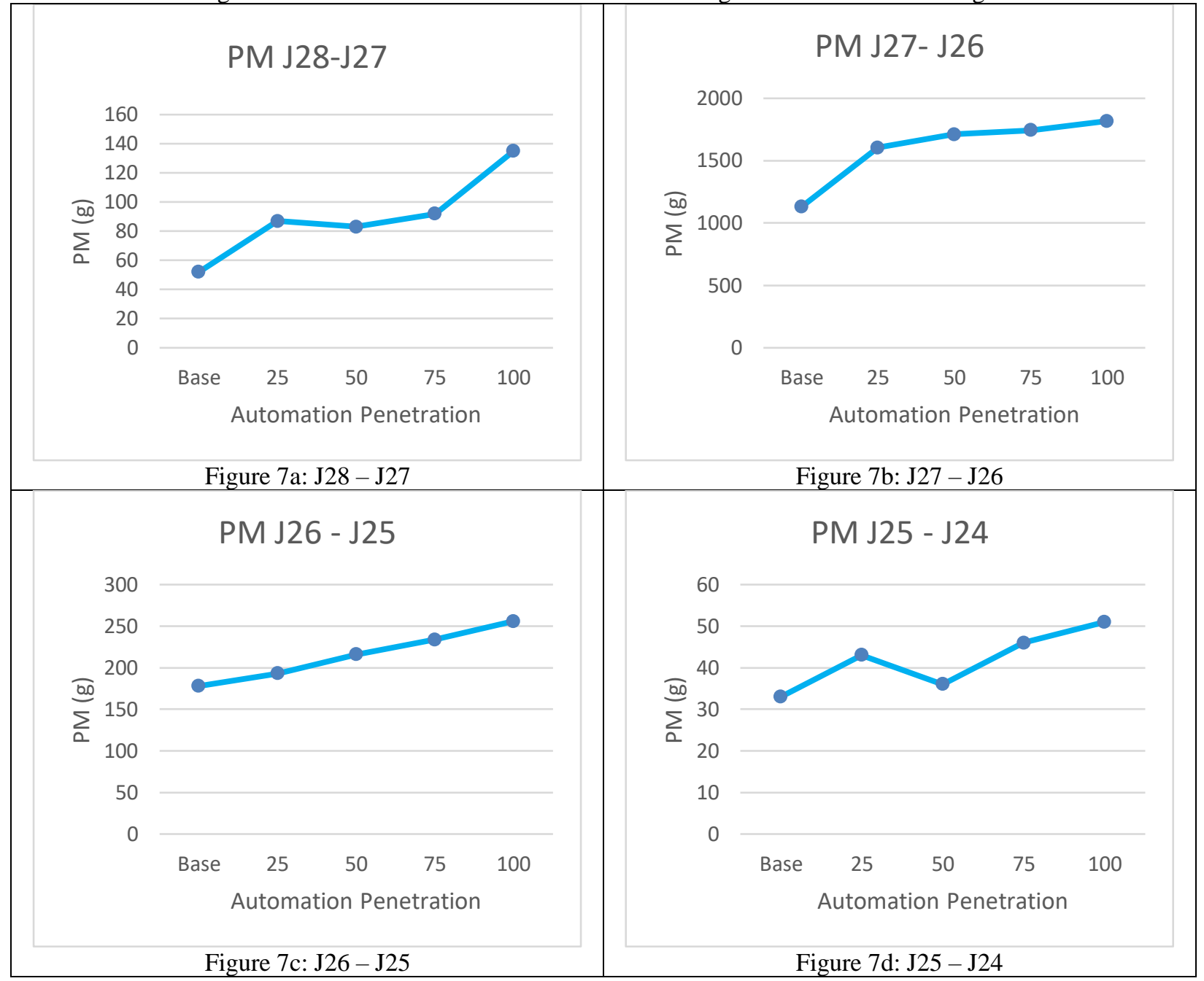




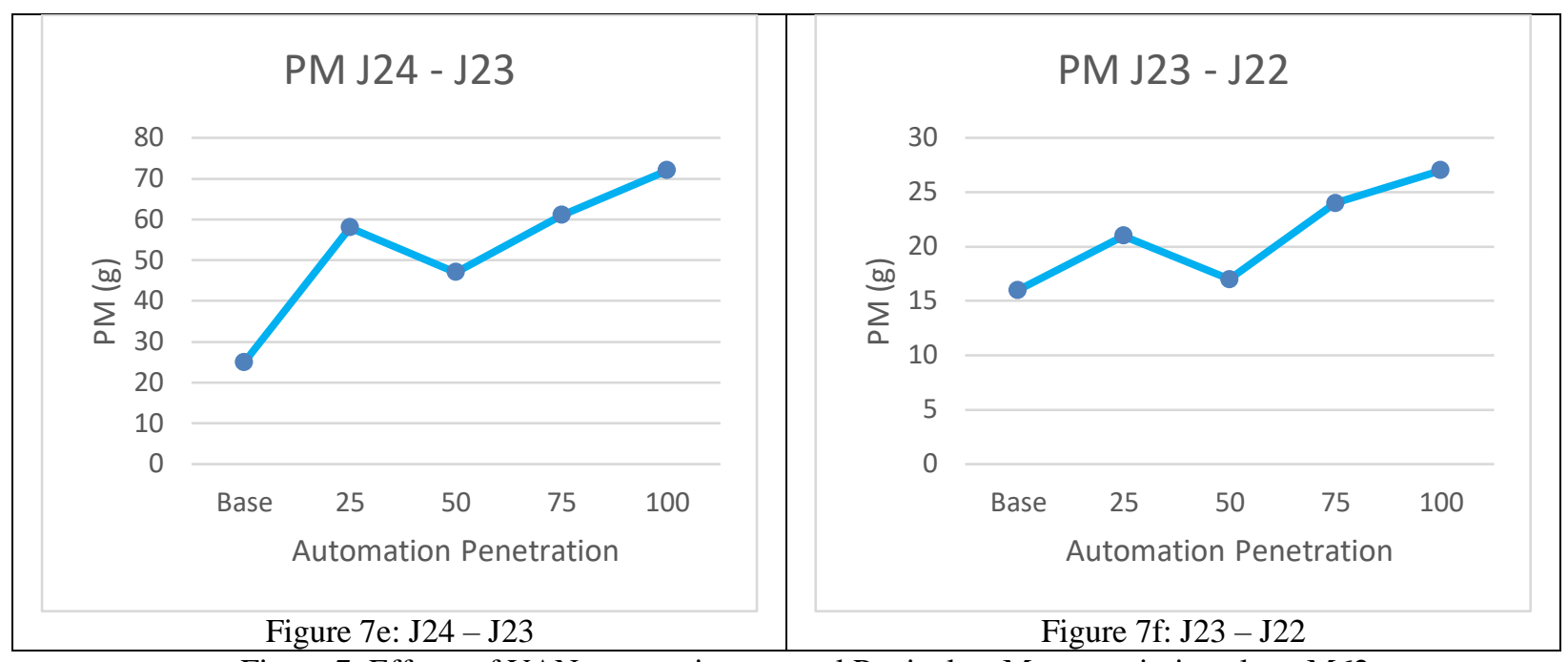

Figure 7: Effects of VAN automation on total Particulate Matter emission along M62

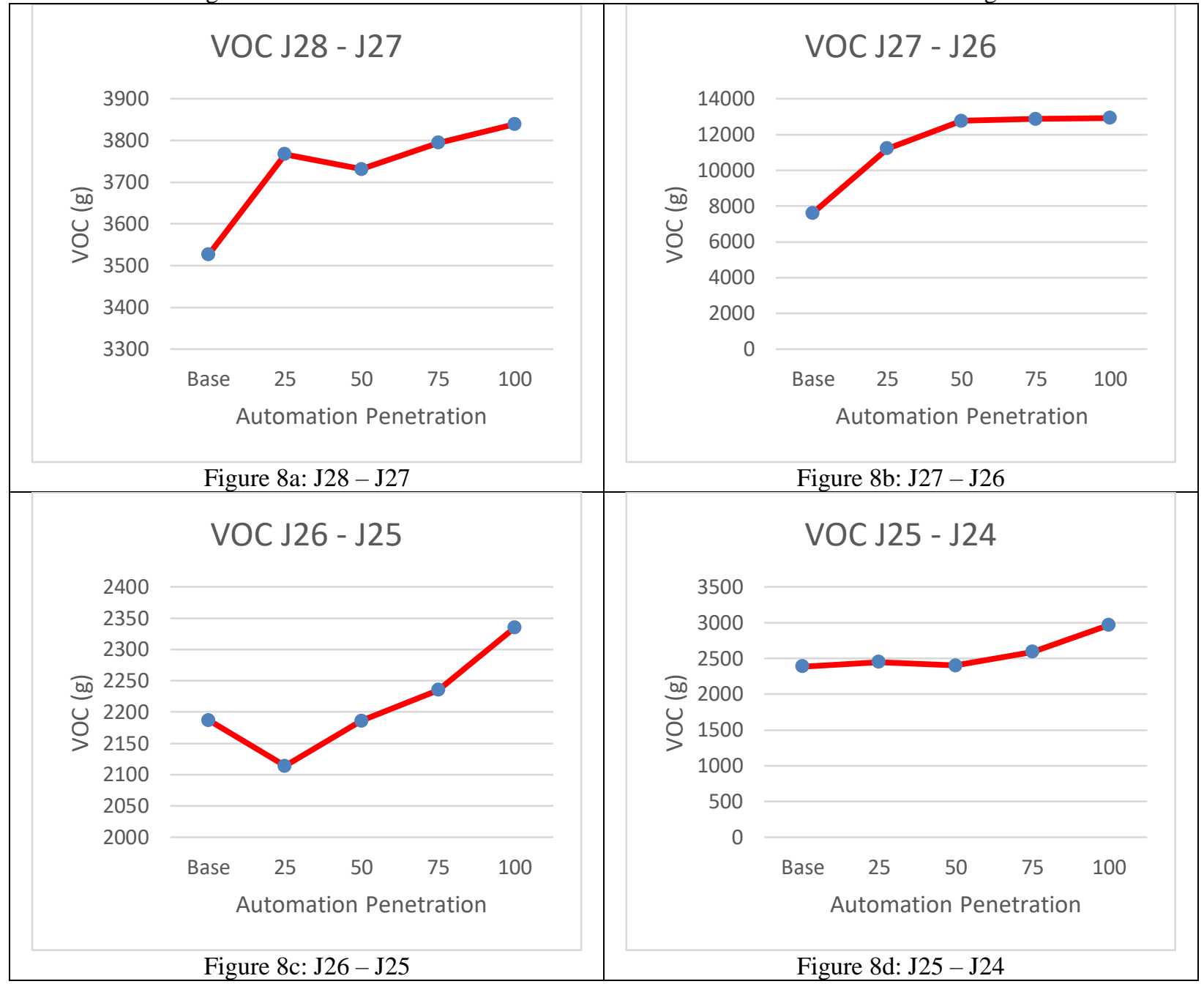




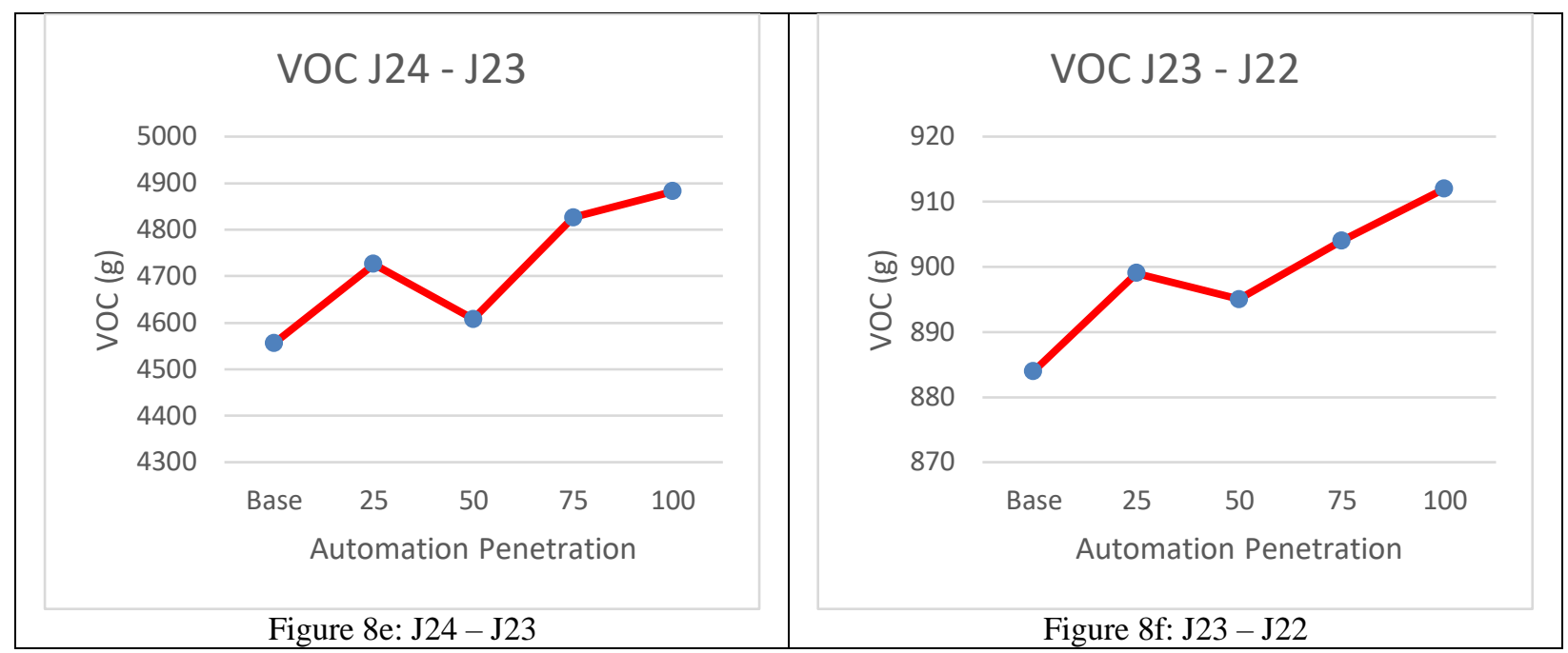

Figure 8: Effects of VAN automation on total VOC emission along M62

For different stretches of the motorway with almost similar property, hints of certain trends for the emission factors could be observed along with the penetration of automated vans. For congested, normal, and uphill stretches along with the motorway, it can be observed that $100 \%$ penetration of automated vans emitted the greatest emission and controversially, $0 \%$ penetration of automated vans emitted the least emission for congested, uphill and normal stretches. This might be possible because of the share of the percentage of vehicle mix of vans in the traffic demand. Due to fewer percentage of vehicle type van along the motorway, automation of vans might create road traffic confusions to conventional vehicles resulting in more frequent accelerations, decelerations and braking, resulting in more emission of environmental factors. It can be observed that the greatest emission along M62 happens at the most congested stretch i.e. J27 - J26 as expected. The general trend observed for environmental emission along van automation penetration is mentioned in Table 10.

Table 10: Emission trends along the stretch when vehicle type VANs are automated

\begin{tabular}{|c|c|c|c|c|c|}
\hline $\begin{array}{l}\text { Stretch } \\
\text { Characteristic }\end{array}$ & \multicolumn{5}{|c|}{$\begin{array}{l}\text { Decreasing level of en } \\
\text { automation penetration }\end{array}$} \\
\hline & \multicolumn{5}{|c|}{ Decreasing Level of Emission } \\
\hline $\begin{array}{c}\text { Congested } \\
\text { Stretch }\end{array}$ & $\begin{array}{l}100 \% \\
\text { (Greatest) }\end{array}$ & $75 \%$ & $25 \%$ & $50 \%$ & $\begin{array}{l}0 \% \\
\text { (Lowest) }\end{array}$ \\
\hline $\begin{array}{l}\text { Uphill Stretch } \\
\text { (Stretch with } \\
\text { slope) }\end{array}$ & $\begin{array}{l}100 \% \\
\text { (Greatest) }\end{array}$ & $75 \%$ & $25 \%$ & $50 \%$ & $\begin{array}{l}0 \% \\
\text { (Lowest) }\end{array}$ \\
\hline Flat Stretch & $\begin{array}{l}100 \% \\
\text { (Greatest) }\end{array}$ & $75 \%$ & $25 \%$ & $50 \%$ & $\begin{array}{l}0 \% \\
\text { (Lowest) }\end{array}$ \\
\hline
\end{tabular}


From the above analysis, the stretch with the maximum congestion (J26- J27) was observed to be the stretch that emits the greatest emission along the motorway and non-uniformity in emission analysis in almost all kinds of stretches were observed. This study highlights that the automation of vans increases the mean speed of travel and reduces the total travel time taken to traverse different stretches of the motorway as observed from section 3.2.1. However, the environmental emission analysis indicates a significant rise in emission values for almost all of the considered scenarios. A possible conclusion about the negative impacts of emitted environmental emission factors is that as lower levels of automated vans are introduced into the existing heterogeneous traffic demand, initial confusions in mixed traffic behaviors within vehicles are developed. This confusion in traffic behavior are developed as a result of the difference between the reaction time, speed profile and speed acceptance characteristics of autonomous and non-autonomous vehicles along with the motorway. This results in non-uniform traffic flows. These initial levels of confusions are expected to reach greater levels as the total percentage of automated vans reaches greater occupancy levels in the motorway, as there still exist a prominent amount of conventional trucks and private cars compared to automated vans in the motorway traffic. This can lead to an increase in difference of vehicle behavior resulting in more amount of frequent accelerations and braking. These conflicts are identified by the non-uniformity in the emission levels represented through figures $5,6,7, \& 8$. The study highlights that when all of the vehicles along the motorway are automated, such conflicts will be reduced and benefits for environmental emissions can be observed in a significant amount which is represented in figure 9 .

When all the vehicles are automated, it can be noted that for the total stretch from Junction 22 to Junction 28 for a distance of approx. $37 \mathrm{~km}$ along M62, 100\% automation of vehicles (total emissions of all vehicle type considered together) gives the least value of emission for all the considered environmental factors.

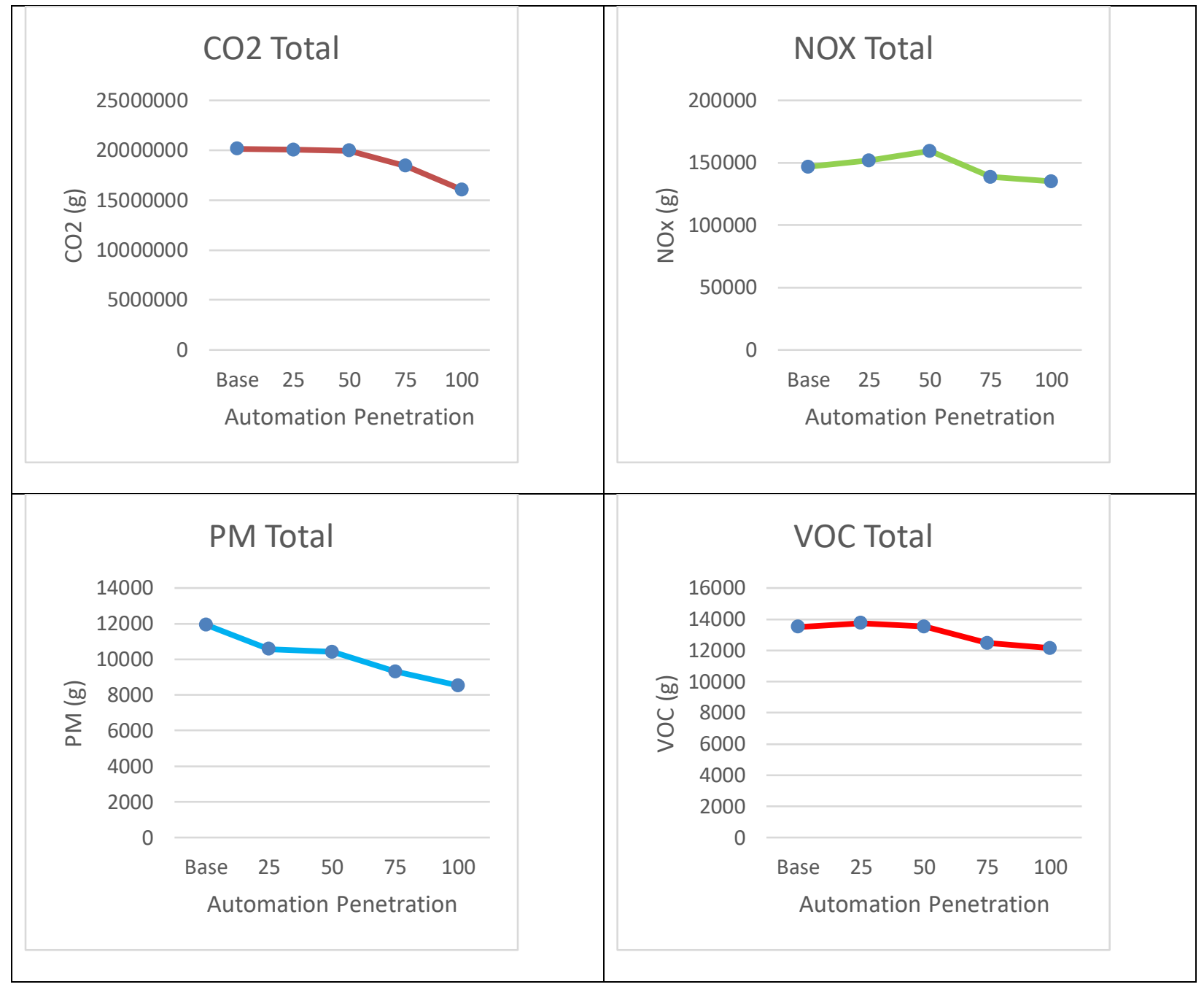


Figure 9: Effects of ALL vehicle automation on Environmental Emission Factors for the motorway M62 (J22 - J28)

\subsubsection{Effects of Gap Distance and Convoy Length on Motorway Speed and Emission}

Figure 10 represents the impact that the gap distance and size of convoy between vehicle type VAN has on the mean speed in a congested and normal stretch of the motorway. For normal stretches, either the gap distance from $4 \mathrm{~m}$ to $10 \mathrm{~m}$ or the size of the convoy from 3 vehicles to 4 vehicles does not seem to have any relevant impact on the mean speed of the vehicles. However, congested stretches (J27 - J26) show some observable changes. If gap width increases, the overall speed of vans along with other non-automated vehicles decreases slightly - this is possibly due to the taking up of extra road space, leaving less space for vehicles to roam about. If convoy size is increased from 3 to 4 , the mean speed of the vans increases a little. This possibly results from the vans driving more closely to each other, making more space available for other vehicles, in this case, the other non-automated vehicles. Thus, the mean speed of other non-automated vehicles is also benefited by them.

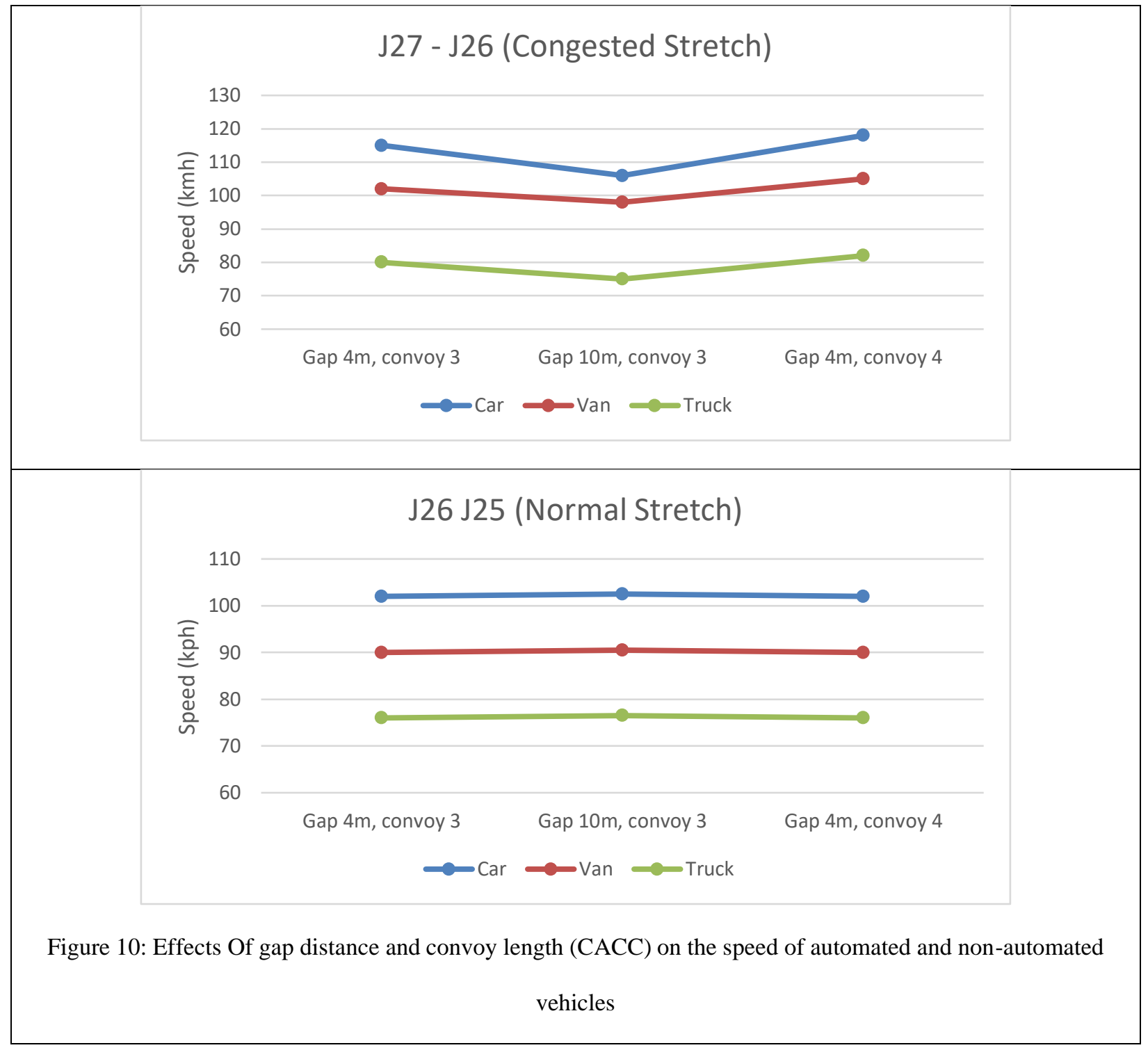

Figure 11 represents the effect of gap distance and convoy length on the mean speed of vehicles on the exit and 
entry ramp. Gap length and convoy length appears to have no significant impacts on the mean speeds of exit and entry ramps of the motorway. This is possibly due to the reflection of the current condition of freight vehicle density in the motorway network M62, and this study hypothesizes that a higher density of freight vehicles may affect the speed and time to enter the motorway. Indeed, the entry speed for vans (which are more frequent and have a higher probability to encounter an automated convoy) falls marginally as the gap between trucks increases to $10 \mathrm{~m}$ from $4 \mathrm{~m}$, which would tend to support our hypothesis. However, further work is necessary in this regard.

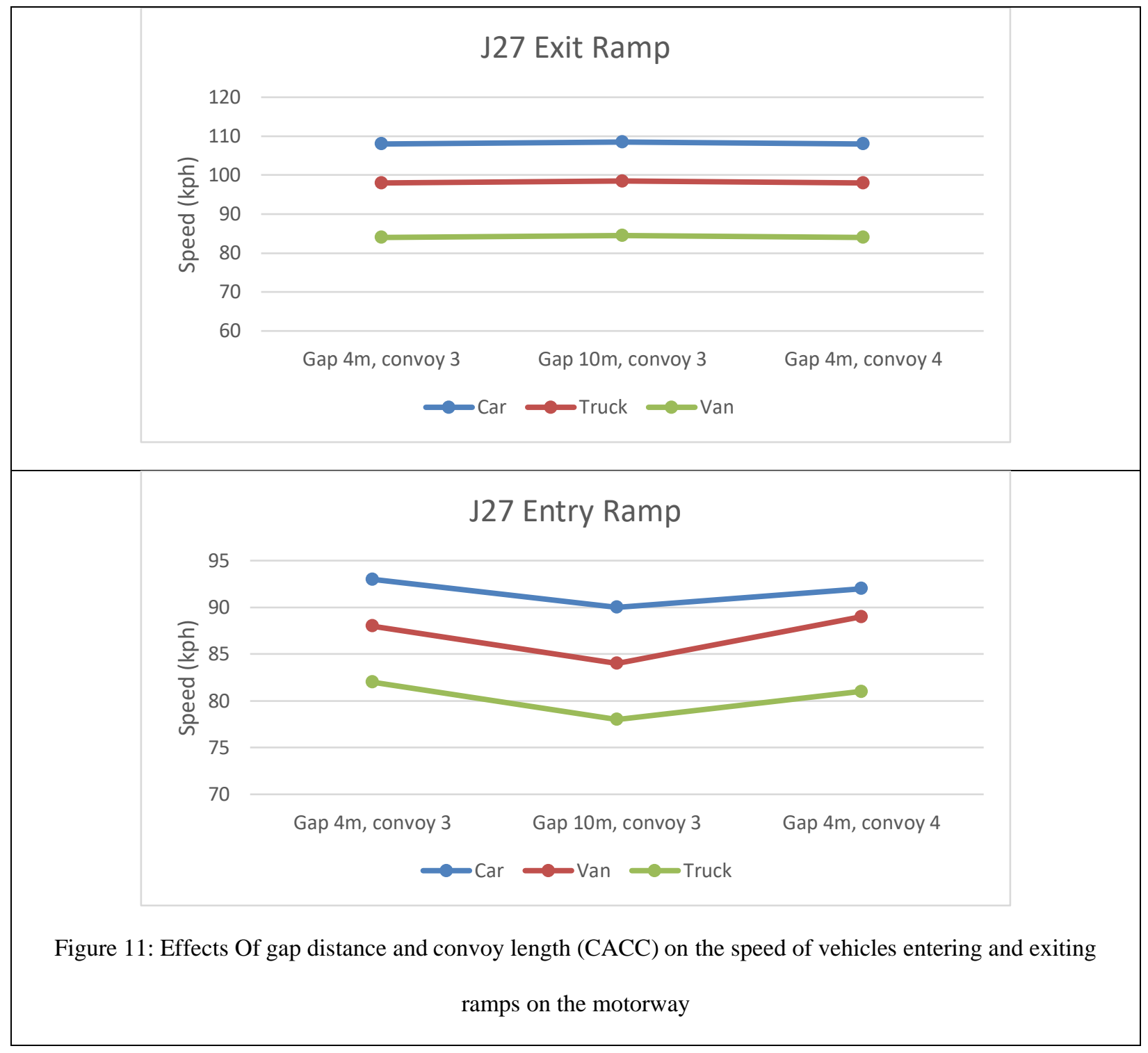




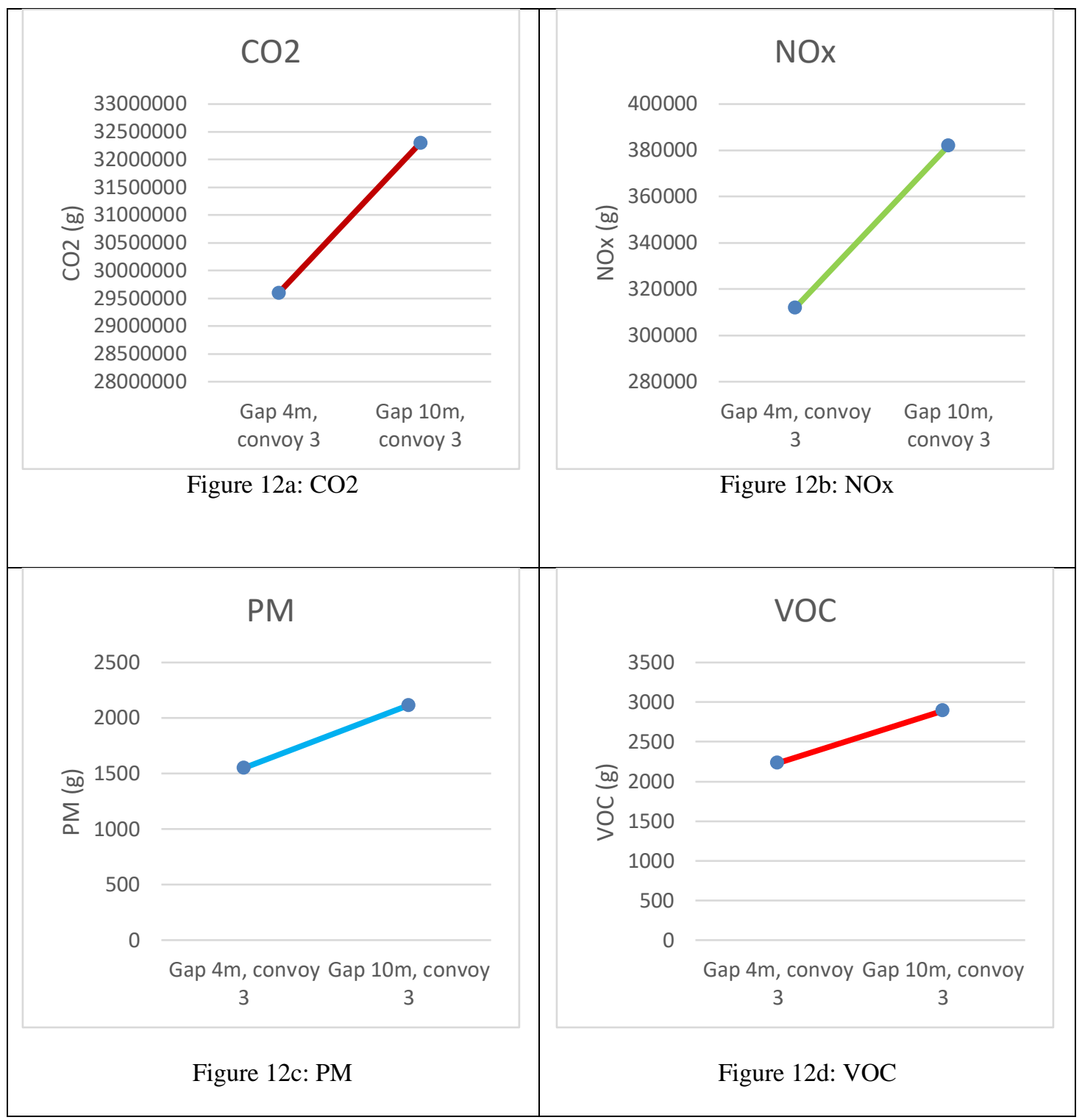

Figure 12: Effects Of gap distance and convoy length (CACC) on emission of Vans

Figure 12 compares the emission results of various environmental factors along the total stretch of the motorway M62 when the same number of vehicle type vans of 3 numbers in convoy are connected with CACC. From the figure, it can be concluded that the gap distance of vehicles impacts the emissions on the road network in a significant manner. Similar trends as stated by Praharaj et al. (Praharaj et al., 2017) and Bibeka et al. (Bibeka et al., 2017) in their studies which concluded that maximum emission benefits from platoons are observed when the gap is considerably short and penetration rates are considerably high are found in our analysis as well. 


\section{CONCLUSION}

\subsection{Summary}

Micro-simulation software Aimsun version 8.3 was used for the simulation purpose of various modeled scenarios described in this research. This study has shown that various traffic parameters such as speed, time/delay are favored with the introduction of higher levels of autonomous technology on vans while negative impacts on environmental emissions are observed. The important conclusions that can be arrived from this study are further divided into two major subdivisions and stated below

\subsubsection{Traffic Parameter Analysis}

- Traffic flow was found to improve with the increase in levels of van automation. Automation of vans in different penetrations along with the motorway benefits speed and travel time for the total stretches of the motorway.

- No negative impacts on the mean speed and travel time were observed from the different levels of automation of vans e.g. in weaving sections, where it might be expected that truck convoys would act as obstructions to the maneuvering of other vehicles and impact the mean speed of other considered vehicle types, such negative impacts were not observed.

- Non-linearity in speed and time benefits are observed concerning the levels of vehicle automation. This non-linearity is more observable along with earlier levels of automation penetration in congested stretches.

- Congested stretch and Up-hill stretches are the most benefited from vehicle automation concerning speed and time.

- Increase in gap width of convoy results in decreased mean speed of vehicles while an increase in convoy length of vehicles with lesser gap length results in increased mean speed of vehicles along the stretch of motorway.

- Gap length and convoy length appears to have no significant impacts on the mean speeds of exit and entry ramps of the motorway.

\subsubsection{Environmental Emission Analysis}

- This study highlight that introducing higher levels of van automation into existing heterogenous motorway traffic leads to increase in vehicle emission. This study hypothesizes that this is probably due to the result of frequent accelerations and braking happening as a result of conflict between vehicle behavior among automated and non-automated vehicles.

- The study hypothesizes that the complete benefits of autonomous vehicles can only be observed after every vehicle class are automated with higher levels of autonomous capabilities. The study analyzes that initial stages after the introduction of automated vehicles on real road network conditions will experience a drastic negative impact on the local air pollutions with benefits observed in traffic parameters such as speed and time. These observed negative impacts are expected to reduce over time with complete automation of all vehicles on the road network.

- Carbon-dioxide emission appears to be the most significant environmental emission factor from vehicles throughout the stretch among the 4 considered factors (CO2, NOx, PM and VOC) and Particulate Matter the least. Thus, stating that, negative impacts of environmental emissions through van automation can possibly lead to increase in global warming by significant amounts.

- It was observed that greater slope results in greater emission values of environmental factors irrespective of the length of the considered stretch. (It was observed that the stretch with the greatest slope (J24 - J23) of length $2250 \mathrm{~m}$ (approx.) emits higher values of emission factors than the stretch with mild slope (J23 - J22) of $11200 \mathrm{~m}$ (approx.). Suggesting that the rate of the slope of the considered stretch can lead to higher negative impacts on emission factors rather than the length of the stretch).

- Particulate Matter emissions are observed to be the highest in congested stretches suggesting that major portions of the Particulate Matter emissions occur from frequent tyre and brake wears resulting from the non-uniform flow of traffic (leading to frequent acceleration and braking) and not just from vehicle exhausts.

- Maximum emission benefits from platoons are observed when the gap is considerably short and penetration rates are considerably high.

Thus, from the overall analysis of the microsimulation conducted along motorway M62, it can be concluded that higher level van automation favors different traffic parameters along the motorway in a 
positive manner. However, the hypothetical situation in which the total traffic demand for scenarios was not changed has to be acknowledged. Importantly, the conclusions that no negative impacts have been analysed on the traffic parameters for automation of vehicles in any of the simulated scenarios and that individual automation of vehicles benefits speed \& travel time with negative impacts on the environmental emission factors are of significant importance.

\subsection{Research Limitations and Future Research Recommendations}

- Demand - For the purpose of this study, a conscious decision was made to not include any potential demand implications of any vehicle class automation that might occur due to the relative changes in the price of automated vehicle transport. How the demand of autonomous vehicles might impact the total traffic flow of road networks are still under studies, thus these changes that might occur in traffic demand due to automation can be included in the future works once everything is precise and clear.

- Van Automation - With taking into account that most of the major automotive companies are working on automation of freight vehicles on larger extends compared, only van was assumed to be automated with higher levels of capabilities. Different impact analyses with other vehicle types can be worked in future and the results found could be compared.

- $\quad$ Single Motorway - This study analyzes the impact of vehicle automation in motorway M62 in the UK with different road characteristics between junctions, more motorways can be simulated in the future and the results found could be compared.

- Emission - London Emission Model was used to analyze the environmental impacts of vehicle automation along the motorway, in the future more environmental model analysis could be carried forward. The emission analysis carried in this study analyzes the total emission impacts from all vehicle classes along the considered motorway. If needed individual vehicle emission analysis from the same motorway could be done in the future.

APPENDIX A

Table A1: Taxonomy of road vehicle automation [32]

\begin{tabular}{|c|c|c|c|c|c|}
\hline \multirow[t]{2}{*}{$\begin{array}{l}\text { Level of } \\
\text { Automation }\end{array}$} & \multicolumn{2}{|l|}{ Human Interference } & \multicolumn{2}{|l|}{$\begin{array}{l}\text { Automated Driving } \\
\text { System }\end{array}$} & \multirow[t]{2}{*}{ Feature } \\
\hline & Operational Function & Capability & Operational Function & Capability & \\
\hline SAE Level 0 & $\begin{array}{l}\text { Lateral and Longitudinal } \\
\text { Control }\end{array}$ & $\mathrm{n} / \mathrm{a}$ & $\begin{array}{ll}- & \text { Localisation } \\
- & \text { Planning } \\
- & \text { Perception } \\
- & \text { Management } \\
\end{array}$ & $\begin{array}{l}\text { All } \\
\text { Driving } \\
\text { Modes }\end{array}$ & $\begin{array}{ll}\text { You } & \text { are } \\
\text { driving } & \end{array}$ \\
\hline SAE Level 1 & $\begin{array}{l}\text { Lateral and Longitudinal } \\
\text { Control }\end{array}$ & $\begin{array}{l}\text { Few } \\
\text { Driving } \\
\text { Modes }\end{array}$ & $\begin{array}{ll}- & \text { Localisation } \\
\text { - } & \text { Planning } \\
- & \text { Perception } \\
- & \text { Management }\end{array}$ & $\begin{array}{l}\text { All } \\
\text { Driving } \\
\text { Modes }\end{array}$ & $\begin{array}{l}\text { You are } \\
\text { driving } \\
\text { (Most } \\
\text { functions } \\
\text { controlled by } \\
\text { driver) } \\
\end{array}$ \\
\hline SAE Level 2 & $\begin{array}{l}\text { Lateral and Longitudinal } \\
\text { Control }\end{array}$ & $\begin{array}{l}\text { Few } \\
\text { Driving } \\
\text { Modes }\end{array}$ & $\begin{array}{ll}\text { - } & \text { Localisation } \\
\text { - } & \text { Planning } \\
\text { - } & \text { Perception } \\
\text { - } & \text { Management }\end{array}$ & $\begin{array}{l}\text { All } \\
\text { Driving } \\
\text { Modes }\end{array}$ & $\begin{array}{ll}\text { You } & \text { are } \\
\text { driving } & \text { (at- } \\
\text { least } & \text { one } \\
\text { driver } & \\
\text { assistant } & \\
\text { system } & \\
\text { automated } & \\
\end{array}$ \\
\hline SAE Level 3 & $\begin{array}{cl}\text { Lateral and Longitudinal } \\
\text { Control } & \\
- & \text { Localisation } \\
- & \text { Planning } \\
- & \text { Perception } \\
- & \text { Management } \\
\end{array}$ & $\begin{array}{l}\text { Few } \\
\text { Driving } \\
\text { Modes }\end{array}$ & $\begin{array}{ll}\text { - } & \text { Management }\end{array}$ & $\begin{array}{l}\text { All } \\
\text { Driving } \\
\text { Modes }\end{array}$ & $\begin{array}{l}\text { You are not } \\
\text { driving (Can } \\
\text { shift between } \\
\text { Safety - } \\
\text { critical } \\
\text { functions to }\end{array}$ \\
\hline
\end{tabular}




\begin{tabular}{|c|c|c|c|c|c|}
\hline & & & & & vehicle) \\
\hline SAE Level 4 & $\begin{array}{cl}\text { Lateral and Longitudinal } \\
\text { Control } & \\
- & \text { Localisation } \\
- & \text { Planning } \\
- & \text { Perception } \\
- & \text { Management } \\
\end{array}$ & $\begin{array}{l}\text { Few } \\
\text { Driving } \\
\text { Modes }\end{array}$ & $\mathrm{n} / \mathrm{a}$ & $\mathrm{n} / \mathrm{a}$ & $\begin{array}{l}\text { You are not } \\
\text { driving (fully } \\
\text { autonomous } \\
\text { but not in } \\
\text { every driving } \\
\text { scenario) }\end{array}$ \\
\hline SAE Level 5 & $\begin{array}{cl}\text { Lateral } & \text { and Longitudinal } \\
\text { Control } & \\
- & \text { Localisation } \\
- & \text { Planning } \\
- & \text { Perception } \\
- & \text { Management } \\
\end{array}$ & $\begin{array}{l}\text { ALL } \\
\text { Driving } \\
\text { Modes }\end{array}$ & $\mathrm{n} / \mathrm{a}$ & $\mathrm{n} / \mathrm{a}$ & $\begin{array}{l}\text { You are not } \\
\text { driving (Fully } \\
\text { autonomous } \\
\text { in every } \\
\text { driving } \\
\text { scenario) }\end{array}$ \\
\hline
\end{tabular}

Note: * Source - (SAE 2016).

Data Availability Statement

Some or all data, models, or code generated or used during the study are proprietary or confidential in nature and may only be provided with restrictions

Acknowledgement

The author would like to thank Dr Zia Wadud and Michael Daly from the University of Leeds, United Kingdom for their continuous support in helping to finish this project efficiently on time. The author would also like to thank $\mathrm{Dr}$ Mithun Mohan from National Institute of Technology, Surathkal, India for his continuous support and appreciate AIMSUN software for providing a license for conducting this study.

References

[1] Johnson, Charlie, and Jonathan Walker. 2016. "PEAK CAR OWNERSHIP THE MARKET OPPORTUNITY OF ELECTRIC AUTOMATED MOBILITY SERVICES.” Rocky Mountain Institute - Mobility Transformation. http://rmi.org/wp-content/uploads/2017/03/Mobility_PeakCarOwnership_Report2017.pdf.

[2] Pendleton, Scott Drew, Hans Andersen, Xinxin Du, Xiaotong Shen, Malika Meghjani, You Hong Eng, Daniela Rus, and Marcelo H Ang.Jr. 2017. "Perception, Planning, Control, and Coordination for Autonomous Vehicles." MDPI - Machines 5 (6). https://doi.org/10.3390.

[3] Shladover, S.E. 2018. "Connected and Automated Vehicle Systems." Journal of Intelligent Transportation Systems 22: 190-200.

[4] Wadud, Zia, P Mackenzie, and P Leiby. 2016. "Help or Hindrance? The Travel, Energy and Carbon Implications of Highly Automated Vehicles.” Transportation Research Part A: Policy and Practice 86: 1-86.

[5] Flämig, H. 2016. Autonomous Vehicles and Autonomous Driving in Freight Transport. Berlin: Springer.

[6] Fagnant, D.J, and K Kockelman. 2015. "Preparing a Nation for Autonomous Vehicles: Opportunities, Barriers and Policy Recommendations." Transp. Res. Part A Policy Pract 77: 167-81.

[7] Ambühl, L, F Ciari, and M Menendez. 2016. "What about Space? A Simulation Based Assessment of AVs Impact on Road Space in Urban Areas." In .

"How Autonomous Vehicles Could Relieve or Worsen Traffic Congestion.” 2017. Here.Com. 2017.

https://www.here.com/sites/g/files/odxslz166/files/2018-

[8] Milakas, D, B van Arem, and B van Wee. 2017. "Policy and Society Related Implications of Automated Driving: A Review of Literature and Directions for Future Research." Ournal of Intelligent Transportation Systems 21 (4): 324-48. https://doi.org/10.1080/15472450.2017.1291351.

[9] Anderson, J.M, K. Nidhi, K.D. Stanley, P Sorensen, C Samaras, and O.A. Oluwatola. 2014. “Autonomous Vehicle Technology: A Guide for Policymakers." Santa Monica: Rand Corporation.

[10] Brown, A, J Gonder, and B Repac. 2014. "An Analysis of Possible Energy Impacts of Autonomous Vehicles.” Road Vehicle Automation.

[11] Alessandrini, A, A Campagna, P Site Delle, F Filippi, and L Persia. 2015. "Automated Vehicles and the Rethinking of Mobility and Cities." Transportation Research Procedia 5: 145-60.

[12] Levine, M.W, and S.D. Boyles. 2015. "Effects of Autonomous Vehicle Ownership on Trip, Mode, and Route Choice." Transportation Research Record Journal of the Transportation Research Board 2493 (1): 29-38. 
[13] Harper, D, C Hendrickson, S Mangones, and C Samaras. 2016. "Estimating Potential Increases in Travel with Autonomous Vehicles for the Non-Driving, Elderly and People with Travel-Restrictive Medical Conditions." Transport Research Part C 72: 1-9.

[14] Maurer, M, J.C. Gerdes, B. Lenz, and H Winner. 2016. Autonomous Driving. Vol. 10. Berlin: Springer.

[15] Wadud, Z. 2017. "Fully Automated Vehicles. a Cost of Ownership Analysis to Inform Early Adoption." Transport Research Part A 101: 163-76.

[15] Chan, C Y. 2017. "Advancements, Prospects, and Impacts of Automated Driving Systems." International Journal of Transportation Science and Technology 6 (3): 208-16.

[16] Taiebat, M, A Brown, H.R. Safford, S Qu, and M Xu. 2018. "A Review on Energy, Environmental, and Sustainability Implications of Connected and Automated Vehicles." Environmental Science and Technology 52 (20): 11449-65.

[16] Khan, A, C.D. Harper, C.T. Hendrickson, and C Samaras. 2019. "Net-Societal and Net-Private Benefits of Some Existing Vehicle Crash Avoidance Technologies." Accident Analysis \& Prevention 125: 207-16.

[17] Bansal, P, and K Kockelman. 2017. "Forecasting Americans' Long-Term Adoption of Connected and Autonomous Vehicle Technologies." Transportation Part A 95: 49-63.

[18] Litman, Todd. 2017. “Autonomous Vehicle Implementation Predictions.” Victoria, BC: Victoria Transport Policy Institute.

[19] Godoy, J, J Perez, E Onieva, J Villagra, V Milanes, and R Haber. 2015. “A Driverless Vehicle Demonstration on Motorways and in Urban Environments." Transport 30 (3): 252-63.

[20] Paden, B, M Čáp, S.Z Yong, D Yershov, and E Frazzoli. 2016. "A Survey of Motion Planning and Control Techniques for Self-Driving Urban Vehicles.” IEEE Transactions on Intelligent Transportation Systems 1 (1): 33-55.

[21] Metz ID, David. 2018. "Developing Policy for Urban Autonomous Vehicles: Impact on Congestion." Urban Science - MDPI 2: 33.

[22] Soteropoulus, A, M Berger, and F Ciari. 2019. "Impacts of Automated Vehicles on Travel Behaviour and Land Use: An International Review of Modelling Studies.” Transport Review 39: 29-49.

2017.12/HERE_How_autonomous_vehicles_could_relieve_or_worsen_traffic_congestion_white _paper.pdf.

[23] Arbib, James, and Tony Seba. 2017. "Rethinking Transportation 2020-2030.The Disruption

of Transportation and the Collapse of the Internal-Combustion Vehicle and Oil Industries

Disruption, Implications and Choices.” A RethinkX Sector Disruption Report. Rethink

Transportation.

[24] Benenson, R, S Petti, T Fraichard, and M Parent. 2008a. "Towards Urban Driverless Vehicles." International Journal on Vehicle Autonomous System 6 (2): 4-23.

[25] Kyriakidis, M, R Happee, and J.C de Winter. 2015. "Public Opinion on Automated Driving: Results of an International Questionnaire among 5000 Respondents." Transport Research Part F: Traffic Psychology Behaviour 32: 127-40.

[26] ICE. 2020. “UK Motorways.” Instituition of Civil Engineers. 2020. https://www.ice.org.uk/what-is-civilengineering/what-do-civil-engineers-do/uk-motorways.

[27] Gips, P. 1981. "A Behavioural Car-Following Model for Computer Simulation.” Transportation Research Part B: Methodological 15: 105-11.

[28] SAE. 2016. "Taxonomy and Definitions for Terms Related to Driving Automation Systems for On-Road Motor Vehicles.”2016. http://standards.sae.org/j3016_201609.

List of Tables

\begin{tabular}{|l|l|}
\hline Table 1 & Vehicle Classification \\
\hline Table 2 & Vehicle Speed Profile \\
\hline Table 3 & Average Simulated vs. Measured Flows Along the Stretch (veh/hr) \\
\hline Table 4 & Deceleration Profiles of Vehicles \\
\hline Table 5 & Acceleration Profiles of Vehicles \\
\hline Table 6 & Vehicle Weight Profile \\
\hline Table 7 & Speed Acceptance of Vehicle \\
\hline Table 8 & Reaction Time of Vehicle \\
\hline Table 9 & Modelled Scenarios - VAN Vehicle Classification Automated \\
\hline Table 10 & Emission trends along the stretch when vehicle type VANs are automated \\
\hline
\end{tabular}


List of Figures

\begin{tabular}{|l|l|}
\hline Figure 1 & M62 Motorway (Study Area) \\
\hline Figure 2 & The merging of motorways M606 and M621 into M62 \\
\hline Figure 3 & Effects of VAN automation on mean speed of different vehicle types along M62 \\
\hline Figure 4 & Effects of VAN automation on normalized travel time along M62 \\
\hline Figure 5 & Effects of VAN automation on total carbon-dioxide emission along M62 \\
\hline Figure 6 & Effects of VAN automation on total Nitrogen-Oxide emission along M62 \\
\hline Figure 7 & Effects of VAN automation on total Particulate Matter emission along M62 \\
\hline Figure 8 & Effects of VAN automation on total VOC emission along M62 \\
\hline
\end{tabular}


